\title{
Learning from the Crowd: Regression Discontinuity Estimates of the Effects of an Online Review Database*
}

\author{
Accepted, The Economic Journal, 5 October 2011 \\ Michael Anderson Jeremy Magruder
}

\begin{abstract}
Internet review forums increasingly supplement expert opinion and social networks in informing consumers about product quality. However, limited empirical evidence links digital word-of-mouth to purchasing decisions. We implement a regression discontinuity design to estimate the effect of positive Yelp.com ratings on restaurant reservation availability. An extra half-star rating causes restaurants to sell out 19 percentage points $(49 \%)$ more frequently, with larger impacts when alternate information is more scarce. These returns suggest that restaurateurs face incentives to leave fake reviews, but a rich set of robustness checks confirm that restaurants do not manipulate ratings in a confounding, discontinuous manner.
\end{abstract}

Beliefs on product quality play an important role in shaping consumer demand. For many goods, consumers face ex ante uncertainty regarding the quality of the good and rely on imperfect signals to infer quality. Traditionally, expert opinion and social learning have helped consumers resolve these information asymmetries. For an expert's take, consumers may consult Consumer Reports when buying an automobile or household appliance or they may read reviews by professional critics when selecting a movie or choosing among dining options. Alternatively, consumers may confer with peers who own the automobile or who have eaten at the restaurant. While friends and other social contacts may be less discriminating than professional critics, their tastes may be more similar to those of prospective consumers. Hoping to capitalise on this possibility, online sites that cheaply

\footnotetext{
*Corresponding author: Michael Anderson, mlanderson@berkeley.edu, 207 Giannini Hall MC 3310, Berkeley, CA 94720-3310, USA. We gratefully acknowledge support from the Giannini Foundation of Agricultural Economics. We thank seminar participants at U.C. Berkeley and U.C. Davis for valuable comments. All errors in the paper are the authors'.
} 
aggregate consumer reviews have recently expanded and have begun supplementing both of the traditional mechanisms.

Economists have recognised the potential of computers to enable large-scale distribution of consumer evaluations for some time (Avery et al., 1999). By reducing the cost of gathering and distributing information, the Internet facilitates social learning among a much broader peer group than has traditionally been possible. It enables lay reviewers to reach large audiences, a capability formerly restricted to professional reviewers. Consumer generated reviews now appear in a wide range of markets. For example, Yelp.com publishes customer reviews of local businesses, TripAdvisor.com publishes traveler reviews of hotels, Amazon.com publishes consumer reviews of products, and Netflix.com displays viewer ratings of movies. However, despite the theoretical potential of digital word-of-mouth to influence consumer choices, limited empirical evidence exists demonstrating its impact on purchasing decisions. In part this is due to the challenge of identifying causal effects of positive reviews on product demand (Angrist and Pischke, 2010). Products that receive positive reviews are ones that appeal to consumers, and these products would likely experience high sales even in the absence of positive reviews.

In this study we leverage a feature of the display system at Yelp.com to estimate the effect of positive Yelp ratings on restaurant customer flows. Yelp allows users to leave reviews of local businesses. As of July 2011, Yelp.com was the $34^{\text {th }}$ most trafficked website in the United States and the $12^{\text {th }}$ most trafficked website in the San Francisco area (the focus of our study), and its rank has been rising over time (Alexa Internet, 2011). When leaving a review on Yelp, a user must assign a rating from one to five stars in whole star increments. Yelp aggregates all reviews for a given business and displays the average rating prominently. However, when Yelp computes the average rating they round off to the nearest half star. Two restaurants that have similar average ratings can thus appear to be of very different quality. For example, a restaurant with an average rating of 3.24 displays a 3-star average rating while a restaurant with an average rating of 3.26 displays a 3.5-star average rating.

We recover the true underlying average rating for each restaurant and use this measure to implement a regression discontinuity $(\mathrm{RD})$ design. We match the Yelp rating data to a database of restaurant reservation availability and estimate the impact of crossing each 0.5-star threshold on reservation availability. Our results indicate that Yelp ratings have 
substantial effects on restaurant customer flows. These impacts appear largest for restaurants for which there is less information on quality available outside of Yelp.

Our estimates imply that restaurants face strong incentives to manipulate their Yelp ratings by leaving fake positive reviews. In principle this manipulation could invalidate the $\mathrm{RD}$ design if savvy restaurateurs heap directly above each Yelp rounding threshold; the assignment of restaurants to either side of the threshold would then no longer be quasirandom. However, we show that a restaurateur's incentive to leave a fake review does not change discontinuously at the Yelp rounding threshold, and a rich set of robustness checks on the density of restaurants and on reviewer characteristics confirm that restaurants are not manipulating ratings in a manner that causes them to fall right above the Yelp rounding threshold.

We open this paper by summarizing the existing literature on consumer learning and discussing our data source, Yelp.com. We then introduce our empirical strategy and document the effect of an increase in Yelp's displayed rating on the availability of tables at

prime dining times. We discuss whether restaurants may attempt to manipulate their Yelp ratings and conduct a range of tests that share a common finding of no evidence of manipulation at thresholds. We then examine the mechanisms by which Yelp may be working and conclude by discussing the magnitude of our estimates.

\section{Background}

A series of existing studies establish the importance of expert opinion and social learning in guiding consumer choices. Reinstein and Snyder (2005) find that positive reviews by professional movie critics increase box office revenue, and Hilger et al. (forthcoming) show that high scores on expert opinion labels increase demand for wines. Social learning, either through observation or word-of-mouth, also impacts consumer demand. Duflo and Saez (2002) and Sorensen (2006) show respectively that an employee's retirement and health plan choices affect the retirement and health plan choices of other employees in the same academic department. Moretti (2011) finds that consumers appear to update their beliefs about a movie's quality based on feedback from peers who have already seen the movie. Cai et al. (2009) show that customers that receive information about a restaurant's most popular dishes tend to order those dishes. 
Online review databases have recently supplemented expert opinion and social learning as a source of information regarding product quality. These databases allow volunteer reviewers to reach large audiences, but it has proven difficult to estimate their effects on consumer demand. A series of experimental and quasi-experimental studies establish the impact of eBay seller ratings on eBay bidder behavior. They find that sellers with better ratings attract more bids or experience higher auction prices (Melnik and Alm, 2002; Jin and Kato, 2006; Resnick et al., 2006; Lucking-Reiley et al., 2007; Cabral and Hortaçsu, 2010). These papers demonstrate that online reviews impact bidder behavior when every bidder observes a seller's average rating and bidders have limited recourse in the event of fraud and no other information about sellers. However, they do not indicate whether reviews can affect consumer behavior in established markets in which consumers can draw information from expert opinion, word-of-mouth, or other signals. A single quasiexperimental study, Chevalier and Mayzlin (2006), examines the effect of customer reviews on sales rankings of books at Amazon.com and Barnesandnoble.com (bn.com). It finds that a book that has better reviews on Amazon.com than it does on bn.com tends to sell better on Amazon.com than it does on bn.com. ${ }^{1}$

This paper builds upon the existing literature on digital word-of-mouth in several respects. First, it examines an established market in which professional reviewers and social learning already play important roles. Second, it employs a regression discontinuity design to estimate the causal effects of positive reviews in a non-experimental setting. Finally, it presents a set of empirical tests for detecting gaming in crowd-sourced online review systems. ${ }^{2}$

\footnotetext{
1 In concurrent but independent work Luca (2011) examines the effect of Yelp.com ratings on restaurant revenues. Our studies differ in data, context, and methods. In comparison to our study, Luca has quarterly data on revenues while we have daily data on reservation availability. His sample focuses on Seattle, a city with low Yelp.com usage in comparison to San Francisco (the focus of our study), and covers 2006 to 2009, a period with low Yelp.com usage (in comparison to 2010). In contrast to our empirical models, the majority of his results rely on fixed effects estimates that are identified off of changes in average review quality over time. $\mathrm{He}$ also conducts statistical inference under the assumption that repeated observations of the same restaurants over time are statistically independent. Both of these choices may increase statistical precision, but they come at the cost of assuming no serial correlation in revenues over time and assuming that changes in review quality are uncorrelated with changes in restaurant quality. In contrast, our paper relies exclusively on RD estimates, and we cluster our standard errors by restaurant, as is customary in the modern panel data literature (Bertrand et al., 2004).

${ }^{2}$ These tests are most applicable to websites that display average ratings in discrete increments. Other examples of websites that display average ratings in half-unit increments are Amazon.com, Barnesandnoble.com, Target.com, and TripAdvisor.com.
} 


\section{Data}

To estimate the effect of Yelp ratings on restaurant reservation availability we merge two independent data sources. The first data set consists of the universe of Yelp reviews for restaurants in San Francisco, California as of February 2011. The second data set consists of reservation availability data taken from a large online restaurant reservation website from July 2010 through October 2010. We focus on San Francisco because it has much higher Yelp usage (measured in terms of numbers of reviews left) than any other city in the United States. As of March 1, 2010, the average restaurant in San Francisco had over three times as many Yelp reviews as the average restaurant in Boston, the city with the highest Yelp usage outside of the San Francisco Bay Area. ${ }^{3}$ The level of Yelp usage in San Francisco today, however, is likely representative of the level of Yelp usage that other cities may experience in several years. From 2005 to 2009, Yelp usage grew at an average rate of $70 \%$ per year across 10 major U.S. cities (Austin, Boston, Chicago, Los Angeles, Las Vegas, New York, San José, San Diego, Seattle, and Washington DC).

When a user browses or searches Yelp.com, Yelp presents her with a list of businesses that meet her search criteria or fall within the category of interest. Figure 1 reproduces a sample search on Yelp.com. Businesses are sorted according to relevance and rating, and for each business the average rating is prominently displayed, rounded to the nearest half star. The number of stars in the average rating is easily visible, particularly because the colour of the stars changes at whole star thresholds. Contact information for the business and a short excerpt from one review are also displayed.

When clicking on an individual business, Yelp.com displays the entire history of reviews for that business. We downloaded this history for each restaurant on Yelp.com and recorded the date of the review, the rating assigned (1-5), and the reviewer's unique user identifier. We then reconstructed the average rating and total number of reviews for each restaurant at every point in time. We accounted for updated reviews when constructing the

\footnotetext{
3 The average reviewed restaurant in San Francisco had 137 reviews while the average reviewed restaurant in the city with the second highest Yelp usage, San Jose, had 57 reviews. Boston averaged 44 Yelp reviews per reviewed restaurant. Chicago, Los Angeles, San Diego, Seattle, and Washington, DC all averaged between 30 and 40 Yelp reviews per reviewed restaurant. Ideally we would observe Yelp page views for each city, but to our knowledge these data are not available. We thus use review activity as a proxy for general Yelp usage.
} 
average rating but did not classify them as new reviews when calculating the total number of reviews. $^{4}$

We augment the Yelp data with reservation availability data from a large online reservation website. This website lists real-time reservation availability for hundreds of restaurants in San Francisco. From July 21, 2010 to October 29, 2010 we recorded reservation availability for a party of four on Thursday, Friday, and Saturday evenings. We checked availability at $6 \mathrm{pm}, 7 \mathrm{pm}$, and $8 \mathrm{pm}$. Availability was measured approximately 36 hours prior to the time of the desired reservation. We merged the reservation availability dataset to the Yelp dataset using restaurant phone numbers. When this method failed or generated duplicate merges, we manually checked for the correct merge.

Table 1 presents summary statistics for two samples. The first sample contains all San Francisco restaurants on Yelp as of January 2011. The second sample contains the subset of San Francisco restaurants that were also listed on the online reservations website during Fall 2010. The full sample contains 3,953 restaurants, while the subsample with reservation data contains 328 restaurants. The average reviewer's rating is approximately 3.7 in both samples. The average restaurant's rating is 3.50 in the full sample and 3.64 in the subsample with reservation data. Restaurants listed on the online reservations website have substantially more reviews than the average restaurant (452.1 versus 167.9) and received more reviews during the study period ( 9.2 per month versus 5.5 per month). Reservation availability averaged $74 \%$ at $6 \mathrm{pm}, 59 \%$ at $7 \mathrm{pm}$, and $68 \%$ at $8 \mathrm{pm}$.

Both the full sample and the subsample represent selected samples. The full sample only contains restaurants with at least one Yelp review while the subsample only contains restaurants listed on the online reservations website. The latter selection criterion is the one most relevant to our estimates, particularly since virtually all restaurants on the reservations website have at least one Yelp review. If the choice to join the online reservations website is influenced by customer flows, then our RD estimates of the effect of Yelp ratings could be attenuated. The direction of the bias is unaffected by whether joining the online reservations website is positively or negatively related to customer flows. ${ }^{5}$ However, the bias will only

\footnotetext{
${ }^{4}$ If a review is updated once, we observe the original assigned rating and the current rating. If a review is updated two or more times, we only observe the current rating and the rating prior to the current rating. Reviews that are updated two or more times constitute only $0.2 \%$ of all reviews.

${ }^{5}$ First consider the case in which joining the reservations website is positively affected by customer flows. In that case restaurants on the margin of joining the reservations website will join when they lie above a Yelp
} 
arise if Yelp ratings have a causal effect on customer flows. We thus interpret our estimates as lower bounds on the effect of Yelp ratings for restaurants that participate in the online reservation service.

Finally, while Yelp usage is high, not all restaurant patrons use Yelp. Only those who consult Yelp should be affected by Yelp's ratings, so any effects of Yelp on availability can be attributed to this fraction of consumers. If Yelp usage continues to expand in the future, we may reasonably expect Yelp ratings to become more important to restaurant availability than our estimates indicate.

\section{Empirical Model and Results}

We use a regression discontinuity estimator to estimate the effect of Yelp. Specifically, we estimate

$$
y_{i t}=\alpha+\beta * D R_{i t}+\gamma f\left(R_{i t}\right)+\varepsilon_{i t}
$$

where $y_{i t}$ is an indicator for the availability of a reservation for a party of four at a particular hour in restaurant $i$ on date $t, D R_{i t}$ is the rating that Yelp displays next to the restaurant's name, and $R_{i t}$ is the actual average rating of reviews left for that restaurant. Identification in a regression discontinuity model is achieved through assuming that the underlying, potentially endogenous relationship between review quality and restaurant quality is fully captured by the flexible function $f(\cdot)$, and that this relationship does not vary discontinuously at the RD threshold values. Our case is a sharp regression discontinuity, so that $D R_{i t}$ is a step function of the actual rating, $R_{i t}$. Restaurants with ratings of at least 2.75 but less than 3.25 have a display rating of 3 stars, restaurants with ratings of at least 3.25 but less than 3.75 have a display rating of 3.5 stars, and so on for each half-star.

rounding threshold and not join when they lie below a Yelp rounding threshold. This reduces the average customer flows of restaurants lying above a Yelp rounding threshold because marginal restaurants have lower customer flows than the average restaurant that joins. The RD estimate is thus attenuated. Now consider the case in which joining the reservations website is negatively affected by customer flows. In that case restaurants on the margin of joining the reservations website will join when they lie below a Yelp rounding threshold and not join when they lie above a Yelp rounding threshold. This increases the average customer flows of restaurants lying below a Yelp rounding threshold because marginal restaurants have higher customer flows than the average restaurant that joins. The RD estimate is again attenuated. 
To estimate this model, we follow Imbens and Lemieux (2008). At each half-star threshold $\hat{R}$, we restrict the sample to restaurants within some bandwidth of that threshold, normalise $R_{i t}$ by the threshold value so that $\widetilde{R_{l t}}=R_{i t}-\hat{R}$, and regress

$$
y_{i t}=\alpha+\beta * I\left(R_{i t}>\hat{R}\right)+\gamma_{1} * \widetilde{R_{l t}}+\gamma_{2} * \widetilde{R_{l t}} * I\left(R_{i t}>\hat{R}\right)+\varepsilon_{i t}
$$

where $I(\cdot)$ represents the indicator function. Our baseline results use a pooled sample with a bandwidth of 0.25 points; in alternate results we vary the bandwidth and examine each threshold individually.

\subsection{Baseline RD Results}

Figure 2 plots mean 7:00 pm reservation availability by Yelp rating. Panel A focuses on the window where restaurants have either 3 or 3.5 stars; Panel B focuses on the window where restaurants have either 3.5 or 4 stars, and Panel $C$ focuses on the window where restaurants have 4 or 4.5 stars. There are clear jumps in the mean availability at 3.5 and 4 stars, and potentially one at 4.5 stars as well. Moving from 3 to 3.5 stars reduces the likelihood of availability from about $90 \%$ to $70 \%$. A fourth star reduces the likelihood of availability further to $45 \%$, and that possibility drops to $20 \%$ at 4.5 stars. Interestingly, for the most part it appears that a step function is a good approximation to the overall relationship between Yelp ratings and restaurant availability. That is, restaurant availability appears to respond primarily to the displayed rating, and not the latent average review score. Though we have too few restaurants with displayed ratings of 2.5 to be confident in results at the threshold for three stars, it is worth noting that we could make a 7:00 pm reservation at these seven restaurants $97.5 \%$ of the time over our study.

Close inspection of the center panel in Figure 2 reveals that the drop in reservation availability occurs several hundredths of a point before the 4-star threshold (at the bin centered at 3.73 instead of the bin centered at 3.77). This deviation is not surprising as restaurants' average ratings drift over time. A restaurant currently just below the threshold is thus likely to have been above the threshold in the preceding months. If the restaurant is better than average, as restaurants near the 4-star threshold are, then time spent above the threshold in previous periods may increase current customer flows - diners attracted by the 
previous 4-star rating may become repeat customers. ${ }^{6}$ To test this hypothesis, Figure 3 plots reservation availability for a sample that drops restaurants that have spent the majority of the preceding year on the opposite side of the 4-star threshold. The figure becomes noisier due to the reduced sample size, but the drop in reservation availability now exactly aligns with the 4-star threshold.

Table 2 presents the regression analog of Figure 2, estimating equation (2) above. At each threshold, we estimate the probability of being able to make an online reservation 36 hours in advance for table times at six, seven, and eight o'clock. Estimates of the effect of Yelp on 6:00 pm availability are not significant, though the point estimates suggest that there is about a $10 \%$ reduction in $6: 00 \mathrm{pm}$ availability at the three and a half and four star thresholds. The seven o'clock estimates are more significant. Here, moving from three to three and a half stars is associated with being 21 percentage points more likely to have sold out all 7:00 pm tables, and moving from three and a half to four stars makes restaurants an additional 19 percentage points more likely to have sold out all tables. Eight o'clock loses some significance, but the three and a half star threshold is still marginally significant (and estimates are similar in magnitude to the $6: 00 \mathrm{pm}$ threshold). A 19 or 21 percentage point change in availability is a large effect; in Section 5 we explore the likely profit implications of this average change. Moreover, this 20 percentage point effect can be ascribed to the subsample of restaurant patrons who use Yelp: if this sample continues to increase in the future we may anticipate that estimated effects will become even larger.

Given the similarity of estimates across the 3.5 and 4-star thresholds, we pool all thresholds for a more detailed analysis in our primary results, presented in Table 3. Column (1) repeats Table 2's analysis on the pooled sample. Panel A examines the likelihood of being able to make a 6:00 pm reservation while Panels $B$ and $C$ examine 7:00 pm and 8:00 pm reservations respectively. Consistent with Table 2, column (1) indicates that an extra half-star on Yelp makes restaurants sell out their 6:00 pm tables 11 percentage points more frequently, their 7:00 pm tables 19 percentage points more frequently, and their 8:00 pm tables 15 percentage points more frequently, though only the 7:00 pm result is significant at

\footnotetext{
${ }^{6}$ A similar pattern seems less likely at the 3.5-star threshold. Restaurants near the 3.5-star threshold are belowaverage restaurants, so diners attracted by the 3.5-star rating are unlikely to become repeat customers. We thus expect, and observe, no drop in reservation availability before the 3.5-star threshold.
} 
the $5 \%$ level (the 8:00 pm effect is marginally significant, as well). These results are not sensitive to reasonable changes in bandwidth. ${ }^{7}$

\subsection{RD Results by Restaurant Type}

Columns (2) through (5) of Table 3 investigate heterogeneity between restaurants. If Yelp is providing information about new restaurants, that information should be most valuable among restaurants that are unfamiliar to patrons. We divide restaurants into familiar/unfamiliar groupings along two dimensions. First, restaurants with fewer than 500 reviews are likely to be less frequented and less well known than those with more than 500 reviews. Since the Yelp signal does not present a reliable average for firms with very few reviews (and manipulating average review quality may be more feasible for these restaurants), we investigate only the restaurants with at least 100 reviews (though the results are similar if we include restaurants with less than 100 reviews as well). Column (2) examines these less familiar restaurants and finds larger, statistically significant effects at all thresholds. For restaurants with fewer than 500 reviews, an extra half-star on Yelp reduces reservation availability by 20 to 30 percentage points at all three times. In contrast, for restaurants with more than 500 reviews, for whom there is likely less hidden information about quality, there is no discontinuous change at any threshold associated with additional Yelp stars. The difference in these two coefficients (at $7 \mathrm{pm}$ ) is statistically significant at the $10 \%$ level. Nevertheless, restaurants with more than 500 reviews differ from those with fewer than 500 reviews along several dimensions, including mean reservation availability. If restaurants with many reviews were always sold out or always had excess capacity, then it would be difficult for Yelp to affect reservation availability. However, the within-restaurant standard deviation in reservation availability is at least as large in the over 500 review subsample as it is in the under 500 review subsample, suggesting that more restaurants in the over 500 review subsample are on the margin of selling out (and thus could be affected by Yelp).

Of course, Yelp's signal is also more precise for restaurants with more reviews. Under Bayesian updating, one might therefore expect that Yelp's impact should be

\footnotetext{
${ }^{7}$ We estimate the 7:00 pm availability RD coefficient for every bandwidth between 0.10 Yelp stars and 0.25 Yelp stars. The RD coefficient lies between 19 percentage points and 27 percentage points for all bandwidths from 0.13 Yelp stars to 0.25 Yelp stars. Only at bandwidths of 0.12 Yelp stars or less does the RD coefficient fall below 19 percentage points.
} 
increasing in the number of reviews. In practice, however, the signal's precision should not generate meaningful heterogeneity in our estimates. This is because almost all restaurants in our data (94\%) have 100 or more reviews, and the signal's precision is already very high when a restaurant reaches 100 reviews. For example, when comparing a 4-star restaurant with 100 reviews to a 3.5-star restaurant with 100 reviews, a consumer can be $98 \%$ confident that the 4-star restaurant's true average rating (i.e., the probability limit of the sample average rating) dominates the 3.5-star restaurant's true average rating. It is thus unsurprising that consumer response is not increasing in the number of Yelp reviews.

A second test for whether the Yelp effect is due to solving information problems groups restaurants according to whether there are external sources of quality information. Here, we note that quality information is easily available for restaurants which have a Michelin $\operatorname{star}^{8}$ or those which appear in the San Francisco Chronicle's annual Top 100 Restaurants listing. In contrast, crowd-sourced information may be more important for restaurants excluded from these prestigious rankings. Columns (4) and (5) of Table 3 perform the RD analysis on these split samples, and again find that an extra half-star on Yelp reduces reservation availability by 20 to 30 percentage points at all three times for restaurants without external recognition but that the Yelp ranking does not similarly advantage restaurants which have been externally accredited. The difference between the two coefficients (at $7 \mathrm{pm}$ ) is statistically significant at the $1 \%$ level. The scope for reductions in reservation availability at externally accredited restaurants is limited at $7 \mathrm{pm}$ (when mean reservation availability is $11.4 \%$ ), but similar patterns emerge at $6 \mathrm{pm}$ when mean reservation availability is much higher at these restaurants (41.6\%). These heterogeneity results are consistent with the hypothesis that Yelp is most valuable when there is less external information about restaurants, though other differences between the two groups of restaurants may also play some role.

Taken together, the RD analysis suggests that restaurants are more likely to sell out at prime dinner times by a large margin: each extra half star is associated with selling out 20 percentage points more frequently. This effect is strongest where quality information would

\footnotetext{
${ }^{8}$ Here, restaurants that received a Michelin star in either 2009 or 2010 are considered to be Michelin star restaurants. There are 42 restaurants in our sample that received a Michelin star or were listed in the Chronicle Top 100 Restaurants (there is significant overlap between these two categories). The Chronicle Top 100 list applies to the entire San Francisco Bay Area metropolitan area rather than the city of San Francisco, which is why only a minority of restaurants on the list appear in our data.
} 
be most useful, suggesting that Yelp is helping consumers learn about potential new restaurants.

\subsection{Dynamic RD Results}

Given that Yelp ratings appear to influence customer demand, it is possible that crossing a Yelp threshold may affect the future trajectory of a restaurant's average Yelp rating itself. There are two reasons why crossing a Yelp threshold might affect the stream of incoming Yelp reviews. First, restaurants could adjust their prices, food, or service in response to increased customer demand, though results presented in Section 5 suggest that they do not. Second, the marginal customer attracted by a better Yelp rating is likely to be a new customer, and she may be more or less critical of a restaurant in expectation than the average existing customer. If there are enough new customers, and if their preferences are sufficiently different from existing customers, then crossing a Yelp threshold could change the trajectory of a restaurant's average Yelp rating. For example, if new customers tend to be less critical than existing customers, then the average rating will demonstrate "stickiness" after crossing a Yelp threshold. If new customers tend to be more critical than existing customers, then the average rating will demonstrate "reversion" after crossing a Yelp threshold.

We empirically test whether crossing a Yelp threshold has an impact on future Yelp ratings by measuring whether a restaurant's average Yelp rating is more or less "sticky" after the restaurant crosses a Yelp threshold. To implement this test, we construct a two year panel of average Yelp ratings running from January 2009 to January 2011. We define disjoint bins of width 0.03 stars, placed such that all three Yelp thresholds in our data $(3.25,3.75$, and 4.25) lie at bin borders. ${ }^{9}$ This results in 51 bins from 3.01 stars to 4.49 stars. Three of these bins represent "true" Yelp thresholds $(3.25,3.75$, and 4.25 - we refer to bins using their left boundaries), and 48 of them represent "placebo" Yelp thresholds. For each bin we calculate the "reversion rate" to the previous bin within a given number of weeks. For example, an 8 week reversion rate of 0.67 for the 3.22 bin implies that when a restaurant's

\footnotetext{
9 For example, the 17 bins surrounding the 3.25 star Yelp threshold have the following borders: 3.01, 3.04, $3.07,3.10,3.13$, 3.16, 3.19, 3.22, 3.25, 3.28, 3.31, 3.34, 3.37, 3.40, 3.43, 3.46, 3.49.
} 
average rating crosses into the 3.22 bin from below, $67 \%$ of the time it crosses back into the 3.19 bin at some point within the next 8 weeks.

Table 4 presents results on the effects of crossing a Yelp threshold on future Yelp ratings. In each column, we regress the bin-level reversion rate on an indicator for whether a threshold represents a true Yelp threshold and a cubic in the value of the threshold. ${ }^{10}$ Column (1) indicates that the 1 week reversion rate is 1.6 percentage points lower for true Yelp thresholds than for placebo Yelp thresholds. This difference is statistically insignificant and represents $4.9 \%$ of the average 1 week reversion rate. Column (2) indicates that the 8 week reversion rate is also not statistically different at true Yelp thresholds than at placebo Yelp thresholds. ${ }^{11}$ To increase precision, Columns (3) and (4) estimate the same regressions on a larger sample containing all Yelp restaurants with 20 or more reviews (not just restaurants in the reservations database). Although the number of bins in the regression is unchanged, the standard errors drop substantially because the number of underlying restaurants increases from 328 to 2,591. In both columns, the reversion rate is not statistically different at true Yelp thresholds than at placebo Yelp thresholds. Overall there is no evidence that crossing a Yelp threshold has any significant impact on future Yelp ratings. This suggests that restaurants do not significantly alter their prices, food, or service in response to crossing a Yelp threshold and that new customers do not leave markedly different ratings than existing customers.

\section{Robustness}

Identification in the RD model relies on the assumption that potential confounders do not change discontinuously at the RD threshold. In general this assumption is satisfied because units (restaurants) just above the threshold should not differ systematically from units just below the threshold. However, this assumption may fail if restaurants are able to precisely manipulate their location relative to the threshold. In that case, specific types of restaurants, manipulators, may locate directly above the threshold. This can generate bias if these types of restaurants also have higher or lower sell-out rates than other restaurants near

\footnotetext{
${ }^{10}$ Controlling for the cubic of the threshold value does not affect the coefficient of interest but substantially improves the regression's precision.

11 These estimates remain statistically insignificant if we vary the reversion window length (from 1 to 8 weeks) or double the bin width (from 0.03 to 0.06 ).
} 
the threshold. Manipulation is feasible in this context because Yelp is crowd-sourced - any restaurateur can in principle leave himself a 5-star review. Furthermore, the significant increases in business at Yelp thresholds create a strong incentive for restaurants to attempt to manipulate their ratings to fall above a threshold.

Yelp attempts to prevent this behavior through several mechanisms. They require potential reviewers to create an account (preventing automated programs from entering many positive reviews), and they engage in filtering behavior that excludes reviews from less established reviewers. Yelp is intentionally vague on the operation of their filtering process in order to keep business-owners from finding loopholes. However, it is likely that some restaurateurs defeat the Yelp filtering process, and this is a challenge to identification that we take very seriously. ${ }^{12}$

Important to our efforts is considering how this manipulation behavior interacts with a regression discontinuity design. If all restaurateurs manipulate their reviews to the greatest extent possible, then the distribution of average ratings will simply shift rightward. Similarly, if restaurateurs near Yelp thresholds attempt to manipulate their average ratings, but they do so on both sides of the threshold, then the density of manipulators will remain continuous across Yelp thresholds. In either case this manipulation behavior will not bias our estimates because the types of restaurants on either side of the threshold will remain comparable to each other. However, if restaurants which are just under the threshold leave a number of self-promoting reviews to get over the threshold, while restaurants that are just over the threshold do not engage in manipulation, then that could create a selection problem at the threshold which would generate biased estimates.

In the appendix we show through a short theoretical model that the incentives to manipulate Yelp ratings are continuous across thresholds. The intuition is simple: given that a random stream of reviews will change each restaurant's average rating over any time period, a restaurant which is just above a threshold has a very similar likelihood of just missing that threshold after new reviews come in as a restaurant which is just below the threshold. Both restaurants therefore face similar incentives to try and push their Yelp scores into safer territory. Thus, while restaurants have strong incentives to manipulate ratings,

12 Continually leaving fake reviews to combat new incoming reviews would quickly grow tedious. More realistically, a restaurateur might outsource the generation of large numbers of fake reviews to another individual or firm. Wang (2010) discusses the strategies that Yelp uses to limit low quality reviews (e.g., "ranting and raving") and marginalise fake reviewers. 
these incentives do not change sharply at Yelp thresholds. This implies that the density of restaurants should be smooth across Yelp thresholds; manipulators should not pile up directly above thresholds.

Of course, restaurateurs may behave in a manner inconsistent with profit maximization for a variety of behavioral reasons, and so we present a variety of empirical tests that consistently show no evidence of any discontinuous manipulation at the threshold. Note, however, that gaming behavior would not intuitively generate the observed reduction in reservation availability at Yelp thresholds. If gaming occurs discontinuously at thresholds, then a subset of restaurants above the thresholds have "true" Yelp ratings that are lower than their observed Yelp ratings. To generate a significant drop in reservation availability at the threshold, these restaurants must sell out virtually all the time, despite the fact that they receive relatively low ratings from true Yelp reviewers. It seems ex ante surprising that a restaurant that receives poor reviews would be extremely crowded, though it is theoretically possible. ${ }^{13}$

\subsection{Empirical Tests for Evidence of Gaming}

Our first set of tests checks for discontinuities at Yelp thresholds in the density of average ratings or in review and reviewer characteristics. If restaurateurs leave additional fake reviews when they are right below Yelp thresholds in order to cross the threshold, then more restaurants should fall just above Yelp thresholds than fall just below them. Figure 4 presents graphical evidence that there is no break in the density of restaurants at Yelp thresholds. The figure plots a histogram of observations (restaurant-days) against mean review quality (normalised so that zero corresponds to the nearest Yelp threshold). There is no visually perceptible break in the frequency of observations at zero.

Discontinuous gaming behavior also implies that the characteristics of reviews and reviewers should change sharply at Yelp thresholds - there should be more 5-star reviews and fewer reviews per reviewer above Yelp thresholds. Table 5 presents regression discontinuity estimates of the effect of crossing a Yelp threshold on the density of average

\footnotetext{
13 For example, perhaps restaurateurs who manipulate Yelp ratings are excellent marketers in general. If so, they may be able to attract many customers to their restaurants despite offering relatively poor food and service.
} 
ratings and review and reviewer characteristics. In this table (and Tables 6 and 7), we present specifications that expand the estimation sample along both the time and restaurant dimensions. These expansions greatly improve the precision of our falsification tests and are possible because we are no longer constrained to examining dates and restaurants for which we have reservation availability data. In this sense we stack the deck against ourselves - we employ much greater precision in our falsification tests than we could employ in our main regressions. If we employ the same tests in the subsample with reservation availability data, we reach similar conclusions for all tests.

Panel A of Table 5 uses a two year panel of average Yelp ratings running from January 2009 to January 2011; the level of observation is the restaurant-day. The two year panel increases the number of observations relative to our reservation availability regressions, but our results remain insignificant if we limit the sample to the dates for which we have reservations data. ${ }^{14}$ Panel B restricts the sample to restaurants with 100 to 500 reviews. These restaurants face stronger incentives to game - they benefit the most from crossing Yelp thresholds (see Table 3) and they have better control over their average ratings than restaurants with more than 500 reviews. For maximum precision, Panel $\mathrm{C}$ uses a sample containing all Yelp restaurants with 20 or more reviews from January 2009 to January 2011.

Column (1) implements the McCrary (2008) test for discontinuities in the density of the running variable (the regression version of Figure 4). We modify the test to accommodate panel data by using a cluster bootstrap to estimate the standard errors; each restaurant represents a single cluster (Cameron et al., 2008). The coefficient of 0.137 is statistically insignificant and represents $8.1 \%$ of the level of the density just above the Yelp threshold. The estimated change in the sample containing restaurants with 100 to 500 reviews, reported in Panel B, is 0.110 points $(6.5 \%$ of the level of the density just above the Yelp threshold). The estimated change in the sample containing all Yelp restaurants, reported in Panel C, is 0.063 points $3.5 \%$ of the level of the density just above the Yelp threshold). All estimates are statistically insignificant.

\footnotetext{
14 The results in Table 5 remain statistically insignificant if we limit the sample to dates for which we have reservations data. However, the number of observations drops from 230,880 to 31,657, so the standard errors increase (see Appendix Table A1). There are also no statistically significant coefficients if we individually examine each Yelp threshold - 3.25, 3.75, and 4.25 - rather than pooling all three Yelp thresholds together (see Appendix Table A2).
} 
The density estimates allow us to compute bounds on the potential bias from gaming. Consider the worst-case scenario regarding reservation availability: every restaurant that games its way over the threshold has zero reservation availability. The estimate in Panel A implies that there are $8.1 \%$ fewer restaurants below the threshold than above the threshold. Suppose that this imbalance represents a true effect of gaming despite being statistically insignificant. To achieve a smooth density across the threshold, we must reassign $4 \%$ of restaurants above the threshold to be below the threshold. In the worst-case scenario, all of these reassigned restaurants have zero availability. The reassignment under this scenario increases 7:00 pm availability above the threshold from 39\% to 40.6\% and reduces 7:00 pm availability below the threshold from 58\% to $55.6 \%{ }^{15}$ The estimated difference in 7:00 pm availability thus drops from 19.1 percentage points to 15.0 percentage points. This result would be marginally significant using the standard error in column (1) of Table 3 . The estimate in Panel B implies that there are 6.5\% fewer restaurants below the threshold than above the threshold. To achieve a smooth density across the threshold, we must reassign $3.2 \%$ of restaurants above the threshold to be below the threshold. In the worst-case scenario, this reassignment increases $7: 00 \mathrm{pm}$ availability above the threshold from $45 \%$ to $46.5 \%$ and reduces $7: 00 \mathrm{pm}$ availability below the threshold from $79 \%$ to $76.4 \%$. ${ }^{16}$ The estimated difference in 7:00 pm availability thus drops from 33.9 percentage points to 29.9 percentage points, which would still be statistically significant using the standard error in column (2) of Table 3. Even under worst-case assumptions, gaming behavior can only explain a small fraction of the observed changes in reservation availability at Yelp thresholds.

Columns (2) through (7) of Table 5 report the effects of crossing a Yelp threshold on review and reviewer characteristics. The regressions in these columns correspond to

\footnotetext{
15 Normalise the number of restaurants near the threshold to 200. Initially, there are 104.2 restaurants above the threshold and 95.8 restaurants below the threshold $(95.8 / 104.2=0.919$, so there are $8.1 \%$ fewer restaurants below the threshold than above). We must reassign 4.2 restaurants (i.e., $4 \%$ of 104.2 ) from above to below to regain balance across the threshold. Observed reservation availability in our data is $39 \%=40.6 / 104.2$ above the threshold and $58 \%=55.6 / 95.8$ below the threshold. Reassigning 4.2 restaurants with no availability from above the threshold to below the threshold changes reservation availability to $40.6 /(104.2-4.2)=40.6 / 100=$ $40.6 \%$ above the threshold and 55.6/ $(95.8+4.2)=55.6 / 100=55.6 \%$ below the threshold.

16 Normalise the number of restaurants near the threshold to 200 . Initially, there are 103.3 restaurants above the threshold and 96.7 restaurants below the threshold $(96.7 / 103.3=0.936$, so there are $6.4 \%$ fewer restaurants below the threshold than above). We must reassign 3.3 restaurants (i.e., 3.2\% of 103.3) from above to below to regain balance across the threshold. Observed reservation availability in our data is $45 \%=46.5 / 103.3$ above the threshold and $79 \%=76.4 / 96.7$ below the threshold. Reassigning 3.3 restaurants with no availability from above the threshold to below the threshold changes reservation availability to $46.5 /(103.3-3.3)=46.5 / 100=$ $46.5 \%$ above the threshold and $76.4 /(96.7+3.3)=76.4 / 100=76.4 \%$ below the threshold.
} 
equation (2), but the dependent variable has been replaced with a review or reviewer characteristic. ${ }^{17}$ Column (2) examines the share of reviews that are 5-stars, as the benefit of a fake review will be minimal or negative if it is not 5 -stars. The results indicate that there is a 0.4 percentage point increase in a restaurant's share of reviews that are 5-stars at the Yelp threshold. This result is statistically insignificant and represents $1.6 \%$ of the average share of reviews that are 5-stars. The equivalent estimates for the 100 to 500 reviews sample and the full sample of Yelp restaurants are 0.8 and -0.4 percentage points respectively and are also statistically insignificant.

Column (3) examines the standard deviation of a restaurant's ratings. Restaurants that receive negative reviews may choose to offset these negative reviews by leaving fake 5star reviews. Alternatively, restaurants that leave many fake 5-star reviews should experience a substantial gap between their observed average ratings and the average ratings left by true reviewers. In either case, the dispersion of a restaurant's ratings will be high if it chooses to game. The results, however, indicate that the standard deviation of a restaurant's ratings increases by only 0.001 stars at the Yelp threshold. This change is statistically insignificant and represents $0.1 \%$ of the average standard deviation of a restaurant's ratings. The equivalent estimates for the 100 to 500 reviews sample and the full sample of Yelp restaurants are also small and statistically insignificant.

Columns (4) through (6) examine the number of reviews per reviewer. Generating fake reviews takes time, so a restaurateur would prefer not to fill an account with fake reviews that do not impact his own restaurant's rating. Column (4) indicates that the average reviewer has 6.3 fewer reviews associated with his account at restaurants just above a Yelp threshold. This difference is statistically insignificant and represents $3.5 \%$ of the average number of reviews per reviewer account. The equivalent estimates for the 100 to 500 reviews sample and the full sample are 5.4 fewer and 4.0 additional reviews respectively and are also statistically insignificant. Column (5) indicates that the share of reviewers who have only one review associated with their accounts is 0.04 percentage points higher at restaurants just above a Yelp threshold, while column (6) indicates that the share of reviewers who have five

\footnotetext{
${ }^{17}$ In these regressions we include the raw level of a restaurant's average Yelp rating - i.e., the version of the running variable that has not been normalised around the closest Yelp threshold - in addition to the normalised running variable that equals 0 at the closest Yelp threshold. Including the raw level of a restaurant's average Yelp rating has little impact on the coefficients but dramatically increases the precision in cases in which the average Yelp rating is highly predictive of the dependent variable (the resulting regression thus has a high $R^{2}$ and low MSE).
} 
or less reviews associated with their account is 0.22 percentage points lower at restaurants just above a Yelp thresholds. These differences are statistically insignificant and represent $4.2 \%$ and $3.5 \%$ of the respective average shares. The estimates for the 100 to 500 reviews sample and the full sample of restaurants are also small and insignificant.

Column (7) examines the difference between a reviewer's rating for a given restaurant and the average rating that the same reviewer leaves at other San Francisco restaurants. A restaurateur who wishes to maximise the return on each fake Yelp account should leave a positive review of his own restaurant and negative reviews of competing restaurants. Column (7) thus tests whether $r_{i j}-\bar{r}_{j}$ changes discontinuously as restaurant $i$ s average rating crosses a Yelp threshold, where $r_{i j}$ is the rating of restaurant $i$ left by reviewer $j$ and $\bar{r}_{j}$ is reviewer $j$ 's average rating of other restaurants. ${ }^{18}$ The estimates indicate that the difference between a reviewer's rating of restaurant $i$ and the average rating that the same reviewer leaves at other restaurants increases by 0.02 Yelp stars when crossing a Yelp threshold. This difference is statistically insignificant and represents $0.6 \%$ of the average rating. ${ }^{19}$ The estimates for the 100 to 500 reviews sample and the full sample of restaurants are even smaller (0.003 and 0.002 Yelp stars respectively) and remain statistically insignificant.

The inspection of the density of average ratings and review and reviewer characteristics reveals no evidence of gaming occurring discontinuously at Yelp thresholds. An alternative test for gaming near Yelp thresholds examines the speed at which a restaurant's average rating rises as it nears a Yelp threshold. If restaurateurs accelerate their gaming efforts when their restaurants lie just below a Yelp threshold, then a restaurant's average rating should rise faster when it lies just below a Yelp threshold than it does at other points. To implement this test, we collapse the two year panel data set to disjoint bins of width 0.03 stars, placed such that all three Yelp thresholds in our data $(3.25,3.75$, and 4.25) lie at bin borders. This is the same data set we used when examining the dynamic properties of average Yelp ratings in Table 4, and it contains 51 bins from 3.01 stars to 4.49 stars. Three

\footnotetext{
18 Since the purpose of the test is to detect reviewers who have written a non-trivial number of reviews focusing on restaurants competing within the same market, we compute $r_{i j}-\bar{r}_{j}$ for all reviewers $j$ with at least six reviews, the majority of which are left for San Francisco restaurants (the universe of potential competitors). However, the results in Table 5 are unchanged if we instead compute $r_{i j}-\bar{r}_{j}$ for all reviewers $j$.

19 The mean of the dependent variable, -0.056 , is of limited interest because it must be close to zero by construction for the entire sample.
} 
of these bins - 3.22, 3.72, and 4.22 - lie just below Yelp thresholds (we refer to bins using their left boundaries). The other 48 bins do not lie just below Yelp thresholds. For each bin we calculate the proportion of restaurants that reach the next bin within a given number of weeks after entering the initial bin. This proportion should be higher for the bins starting at $3.22,3.72$, and 4.22 if restaurateurs accelerate their gaming efforts when their restaurants lie just below a Yelp threshold.

Table 6 presents results on the effects of entering a rating bin just below a Yelp threshold. In each column, we regress the proportion of restaurants that enter the next bin within 1 or 8 weeks on an indicator for whether the bin lies at 3.22, 3.72, or 4.22 and on a cubic in the value of the bin. ${ }^{20}$ Column (1) indicates that the probability of crossing to the next bin within 1 week of entering the initial bin is 1.1 percentage points lower just below a Yelp threshold than at other points. This difference is statistically insignificant and represents $8.9 \%$ of the average 1 week crossing rate. Column (2) indicates that the probability of crossing to the next bin within 8 weeks of entering the initial bin is 3.9 percentage points lower just below a Yelp threshold than at other points. This difference is statistically insignificant and represents $13.2 \%$ of the average 8 week crossing rate. These estimates remain statistically insignificant if we vary the crossing window length (from 1 to 8 weeks) or double the bin width (from 0.03 to 0.06). Columns (3) and (4) present analogous results estimated on the sample of restaurants with 100 to 500 reviews, while columns (5) and (6) present analogous results estimated on the sample of all Yelp restaurants. In all columns the average crossing rates in bins just below Yelp thresholds are not statistically different than the average rates in other bins.

\section{Interpretation of RD Effects}

Section 4 establishes that the observed changes in reservation availability at Yelp thresholds represent causal effects. However, several questions emerge when considering these effects. First, do the effects represent the transmission of information on restaurant quality or do they represent a marketing effect generated by Yelp's ranking system? Second, do the effects on reservation availability translate into changes in customer visits? Third, do

\footnotetext{
${ }^{20}$ Controlling for the cubic of the initial bin value does not affect the coefficient of interest but improves the regression's precision.
} 
restaurants react to crossing a Yelp threshold in a manner that affects the observed change in reservation availability? Finally, what changes in customer flows and profits are consistent with the observed changes in reservation availability? We present evidence on each of these questions in this section.

\subsection{Information on Quality Versus Marketing}

The RD estimates may not represent a pure effect of information regarding restaurant quality if the order in which Yelp lists restaurants on its website is a function of a restaurant's displayed average rating rather than its true average rating. ${ }^{21}$ In that case, restaurants just above a Yelp threshold would be significantly more likely to be seen by consumers browsing Yelp than restaurants just below a Yelp threshold. To examine whether crossing a Yelp threshold affects the order in which a restaurant appears on Yelp, we implement a variant of our RD regression from equation (2) that specifies a restaurant's Yelp listing order (i.e., the order in which it appears on Yelp.com) as the dependent variable.

Table 7 presents estimates of this regression for both restaurants with reservation data and all San Francisco Yelp restaurants. ${ }^{22}$ Column (1) indicates that crossing a Yelp threshold increases (i.e., makes worse) a restaurant's Yelp listing order by 42 places on average. This estimate is statistically insignificant and represents $2.9 \%$ of the average listing order. Column (2) includes as a covariate a restaurant's rank as determined by its Yelp rating (i.e., the top rated Yelp restaurant receives a rank of 1, the second highest rated Yelp restaurant receives a rank of 2 , etc.). This increases precision because the relationship between a restaurant's listing order and its Yelp rating is nonlinear; in particular, it changes according to the density of restaurants at different Yelp rating levels. In contrast, the ranking by Yelp rating is more uniformly predictive of the Yelp listing order. Crossing a Yelp threshold now decreases (i.e., improves) a restaurant's Yelp listing order by 16 places on average. This estimate is statistically insignificant and represents $1.0 \%$ of the average listing order. Columns (3) and (4) estimate the same models as the first two columns on the sample

\footnotetext{
${ }^{21}$ Such an algorithm would be surprising in that it would require more code to write than an algorithm that simply uses the true average rating. Using the displayed average rating would result in an enormous number of ties, so it would be necessary to sort both on displayed average rating and true average rating. Of course, after conditioning on the true average rating, there is no additional information contained in the displayed average rating.

22 The Yelp listing order data and average Yelp ratings were recorded on January 3, 2011.
} 
that includes all restaurants. Crossing a Yelp threshold decreases a restaurant's listing order by a statistically insignificant $0.3 \%$ in both cases. The $R^{2}$ in all regressions ranges from 0.95 to 0.98 , indicating that listing order is almost entirely determined by average rating (the other factors that appear to have some impact are number of reviews and geographic proximity). Since the Yelp thresholds have no effect on restaurant listing order, the placement of restaurants among Yelp search results is continuous across thresholds, and the RD effects must reflect the transmission of information regarding restaurant quality. We thus conclude that increased information about restaurant quality causes higher-rated restaurants to have lower availability, rather than any effect of increased visibility.

\subsection{Substitution Between Walk-ins and Reservations}

Though Yelp ratings affect reservation availability, it is possible these changes occur only because customers who would have otherwise walked in now make reservations. If consumers react to Yelp ratings by assuming that higher rated restaurants are more likely to have long waits, they may make extra effort to book a reservation. However, high Yelp ratings alone may not be sufficient to draw them to a restaurant that they otherwise would not visit. Under this behavior, crossing a Yelp threshold would reduce both reservation availability and peak customer flows. Reservation availability would fall as consumers react to the higher displayed Yelp rating. Peak customer flows would fall as consumers who would have made reservations at the lower displayed Yelp rating now find the restaurant to be fully booked and choose to dine at other locations or times.

To test whether Yelp ratings affect consumers' propensity to book reservations without changing customer flows, we surveyed wait times for a random subset of restaurants lying near (within 0.2 stars) the 3.25 Yelp threshold over two weekends in February 2011. We chose the 3.25 threshold because it displayed the largest changes in reservation availability. Because there are more restaurants above 3.25 stars than below 3.25 stars, we surveyed every restaurant between 3.05 to 3.24 stars and a random $60 \%$ subsample of restaurants between 3.25 to 3.45 stars. The resulting sample contained 21 restaurants below 3.25 stars and 29 restaurants above 3.25 stars. On two Friday evenings and one Saturday evening a research assistant called restaurants in the sample between 6:30 and 7:30 pm. Each restaurant was called at least once, and the order of calls was randomised. At each restaurant 
the research assistant asked how long a party of four would need to wait for a table if they arrived within 15 minutes. In some cases restaurants reported that the expected wait time exceeded one hour and gave an estimate of a time at which seating would definitely be available. In these cases we recorded both the number of minutes between the current time and the time at which seating would definitely be available and a version of the same variable that was top-coded at 60 minutes. The raw correlation between wait time and reservation availability was large and statistically significant. Restaurants with no reservation availability reported waits that were 34 minutes longer using the raw wait time variable $(t=2.4)$ and 20 minutes longer $(t=2.4)$ using the top-coded wait time variable. ${ }^{23}$ Both differences are more than $100 \%$ of the average wait time and top-coded wait time respectively.

Table 8 presents RD estimates of the effects of crossing the Yelp threshold on restaurant wait time. Each regression controls for a restaurant's average Yelp rating, the average rating interacted with an indicator for being above the threshold, the time of day at which a restaurant was called, and indicators for each day in the sample. ${ }^{24}$ Column (1) indicates that crossing the Yelp threshold increases top-coded wait time by 27 minutes. This effect is statistically significant and represents $189 \%$ of the average top-coded wait time. Of course, many restaurants report no wait. Column (2) presents estimates from a Tobit version of the regression in column (1); under certain assumptions, the coefficient in column (2) may be interpreted as the effect of crossing the Yelp threshold on wait time conditional on a restaurant having any wait. ${ }^{25}$ The coefficient in the Tobit model is 131 minutes and is marginally significant; the coefficient is substantially larger than in column (1) because the dependent variable is both top-coded and bounded below at zero. Columns (3) and (4) estimate the same models using raw wait time as the dependent variable. The least squares estimate in column (3) is marginally significant and implies that crossing the Yelp threshold increases wait time by 49 minutes. The Tobit estimate in column (4) is statistically significant and implies that crossing the Yelp threshold increases wait time by 120 minutes conditional

\footnotetext{
23 Wait time is bounded below at zero (and bounded above at 60 for the top-coded version of the variable). Tobit versions of the same regressions generate estimates of 73 minutes $(t=2.8)$ and 83 minutes $(t=2.0)$ respectively.

24 Controlling for time of day called and the day indictors increases precision but has little impact on the coefficient estimates. This is not surprising since time of day and day called were randomised.

${ }^{25}$ Most importantly, crossing the threshold must have no effect on the probability of any wait. If crossing the threshold affects the probability of any wait, then the "causal effect" of crossing the threshold on wait time conditional on any wait becomes difficult to define. This assumption is unlikely to literally be true, so we are more interested in the sign and significance of the Tobit estimates than in the magnitude of the Tobit coefficients.
} 
on the restaurant having any wait. Column (5) estimates the effect of crossing the Yelp threshold on the probability of experiencing any wait. Crossing the Yelp threshold increases the probability of any wait by 44 percentage points, but the difference is not statistically significant.

The results from the wait time regressions reveal no evidence that wait times decrease when crossing a Yelp threshold. To the contrary, the coefficient of interest in every regression is positive, and two are statistically significant at the $5 \%$ level. We thus conclude that Yelp ratings affect both customer flows and the probability of booking a reservation.

\subsection{Effects on Restaurant Behavior}

It is possible that restaurants respond to higher Yelp ratings by changing the quality of food or service provided, perhaps most plausibly as a response to increased consumer demand. In that case, our RD estimates remain valid, but the exact channel for the increase in restaurant demand becomes more complicated.

To test this hypothesis, we examine whether external ratings change when restaurants cross Yelp thresholds. We have two sources of external ratings: the Zagat guide rating for each restaurant, and the displayed rating from the online reservations database. Unlike Yelp, the online reservations database displays a relatively continuous average rating, with the listed ratings complete up to tenths of a point. Table 9 presents regressions with quality measures as outcomes, considering alternatively the rating in Zagat categories of Food, Décor, Service, and Cost, and the restaurant rating from users of the online reservations database. None of the RD estimates presented in the first row are statistically significant. All are small in magnitude, and there is no pattern to the point estimates. Thus, we conclude that any quality adjustments that restaurants make in response to crossing a Yelp threshold are modest.

\subsection{Potential Effects on Restaurant Profits}

We estimate that an extra half-star on Yelp reduces reservation availability by approximately 19 percentage points. To gauge what changes in customer flows could be consistent with a 19 percentage point change in reservation availability, we performed a 
series of simple statistical calibrations. First, we recorded the capacity of each restaurant in a sample of 73 restaurants. ${ }^{26} \mathrm{Next}$, we assumed that a restaurant has no reservation availability if the number of seats reserved for a given evening reaches its capacity. Finally, we examined the average customer flows that would be consistent with reservation availability rates of $58 \%$ (the average rate above the Yelp thresholds) and 39\% (the average below the Yelp thresholds) under different assumptions about the distribution of arriving customers.

If customer reservation arrivals for each restaurant follow a Poisson process, then the equality between mean arrivals and the variance of arrivals makes it easy to calculate mean customer flows for any given sell out frequency and capacity. For example, a restaurant at the $10^{\text {th }}$ percentile of capacity (40 seats) sells out $58 \%$ of the time when mean customer arrivals are 39.4 per evening and $39 \%$ of the time when mean customer arrivals are 42.8 per evening. The implied change in customer flows that corresponds to the observed change in reservation availability is thus $8.6 \%(42.8 / 39.4=1.086)$. Analogous figures for the median restaurant ( 85 seats) and a restaurant at the $90^{\text {th }}$ percentile of capacity ( 207 seats) are $6.0 \%$ and $3.8 \%$.

Of course, the Poisson process understates the true variance of customer arrivals because customer arrivals are not independent of each other. Customers generally arrive in groups of two to six, and some Thursday or Friday nights may be more popular for dining than other Thursday or Friday nights. If we assume that the true variance of arrivals per evening is twice the Poisson variance, then for the $10^{\text {th }}$ percentile restaurant the implied change in customer flows that corresponds to the observed change in reservation availability is $12.8 \%$. Analogous figures for the median restaurant and the $90^{\text {th }}$ percentile restaurant are $8.6 \%$ and $5.4 \%$ respectively. $^{27}$

These back-of-the-envelope calibrations suggest that the median restaurant might experience a $6 \%$ to $9 \%$ increase in customer flows if its reservation availability drops from $58 \%$ to $39 \%{ }^{28}$. A modest change in customer flows, however, can have a significant impact on profits in an industry with high fixed costs and high margins. For a typical mid-to-high-

\footnotetext{
26 We drew a random sample of 100 restaurants from our data and telephoned each restaurant to inquire about its capacity. Of the 100 restaurants, we were able to reach 73 of them.

${ }^{27}$ If the true variance is twice the Poisson variance, then a $95 \%$ confidence interval for the number of arrivals on a prime dining night at a restaurant that averages 75 arrivals per night is $(50,100)$. If the true variance were even higher, then the implied change in customer flows would increase further.

${ }^{28}$ While in percentage terms these numbers are modest, we note that not all restaurant patrons are Yelp users. Thus, the increased flow as a percentage of patrons that are Yelp users may be much more substantial
} 
end restaurant with $\$ 20,000$ per week in sales and a margin of $68 \%$ on food and beverage sales (National Restaurant Association, 2010), a 6\% increase in revenue translates into a gain of $\$ 816$ per week in pre-tax profit $(\$ 20,000 * 0.06 * 0.68=\$ 816)$. In comparison, the median profitable mid-to-high-end restaurant earns approximately $\$ 2,000$ per week in pre-tax profit (National Restaurant Association 2010). Of course, the increase in profit will be lower if the restaurant is capacity-constrained or if it has to expand staffing levels to maintain service. Nevertheless, the calibrations suggest that a typical restaurant could experience substantial gains in profit when crossing a Yelp threshold. ${ }^{29}$

\section{Conclusions}

Yelp aggregates consumer information on restaurant quality into convenient half-star ratings. We provide evidence that higher ratings cause restaurant to sell out prime-time table 19 percentage points more frequently. These effects are largest for restaurants where information is most scarce; restaurants that are not externally accredited sell out 27 percentage points more frequently when they receive an extra half-star. We find no evidence that these effects are due to manipulation of ratings, changes in restaurant quality, or direct marketing effects of Yelp, and present additional supporting evidence that customer flows change.

These effects are large, and they indicate a valuable use of crowd-sourced information: because Yelp collects and aggregates the experiences of a large number of patrons, Yelp provides a convenient forum to solve asymmetric information problems about the quality of unfamiliar restaurants. In a sense, Yelp represents a highly efficient mechanism for social learning, and thus it is perhaps unsurprising that its effects are so large when social learning effects have been documented in many other less efficient contexts.

Tightening the link between restaurant quality and restaurant patronage may well have positive benefits for society. Crowd-sourced quality information may improve the average quality of consumed meals via two mechanisms. First, it can redirect consumers to

\footnotetext{
29 The effects on profits suggest that restaurants below Yelp thresholds may be more likely to go out of business than restaurants above Yelp thresholds. If restaurants below a Yelp threshold are more likely to go out of business than restaurants above a Yelp threshold, then our RD estimates will be attenuated because more low-performing restaurants will shut down below the threshold than shut down above the threshold. Our tests in Section 4 for discontinuities in the density of restaurants, however, imply that any differential in shutdown rates across Yelp thresholds must be modest.
} 
higher quality restaurants. Second, it can induce lower quality restaurants to shut down or improve their quality in response to changes in customer demand (Cabral and Hortaçsu 2010). We provide direct evidence of the first mechanism, but our identification cannot speak to the second mechanism. While we cannot comment on trends like overall restaurant usage, mean restaurant quality, and restaurant profits, simple theory suggests that decreasing the role of asymmetric information in restaurant choice should be welfare-enhancing. With the rapid spread of Yelp and other similar crowd-sourcing websites, this suggests that market evolution may be an important avenue of future research.

Michael Anderson: Department of Agricultural and Resource Economics, University of California, Berkeley, Berkeley, CA, USA

Jeremy Magruder: Department of Agricultural and Resource Economics, University of California, Berkeley, Berkeley, CA, USA

Date submitted: 3 September 2011

Date conditionally accepted: 20 September 2011

\section{REFERENCES}

Alexa Internet. (2011). 'Yelp.com Site Info', http://www.alexa.com/siteinfo/yelp.com (last accessed: 26 July 2011).

Angrist, J.D. and Pischke, J. (2010). 'The credibility revolution in empirical economics: how better research design is taking the con out of econometrics', Journal of Economic Perspectives, vol. 24(2), pp. 3-30.

Avery, C., Resnick, P. and Zeckhauser, R. (1999). 'The market for evaluations', The American Economic Review, vol. 89(3), pp. 564-584.

Bertrand, M., Duflo, E. and Mullainathan, S. (2004). 'How much should we trust differencesin-differences estimates?', Quarterly Journal of Economics, vol. 119(1), pp. 249-275.

Cabral, L. and Hortaçsu, A. (2010). 'The dynamics of seller reputation: evidence from eBay', The Journal of Industrial Economics, vol. 58(1), pp. 54-78.

Cai, H., Chen, Y. and Fang, H. (2009). 'Observational learning: evidence from a randomized 
natural field experiment', The American Economic Review, vol. 99(3), pp. 864-882.

Cameron, A.C., Gelbach, J.B. and Miller, D.L. (2011). 'Bootstrap-based improvements for inference with clustered errors', Review of Economics and Statistics, vol. 90(3), pp. 414427.

Chevalier, J.A. and Mayzlin, D. (2006). 'The effect of word of mouth on sales: online book reviews', Journal of Marketing Research, vol. 43(3), pp. 345-354.

Duflo, E. and Saez, E. (2002). 'Participation and investment decisions in a retirement plan: the influence of colleagues' choices', Journal of Public Economics, vol. 85(1), pp. 121148.

Hilger, J., Rafert, G., and Villas-Boas, S. (Forthcoming). 'Expert opinion and the demand for experience goods: an experimental approach in the retail wine market', Review of Economics and Statistics.

Imbens, G.W. and Lemieux, T. (2008). 'Regression discontinuity designs: a guide to practice', Journal of Econometrics, vol. 142(2), pp. 615-635.

Jin, G.Z. and Kato, A. (2006). 'Price, quality, and reputation: evidence from an online field experiment', The RAND Journal of Economics, vol. 37(4), pp. 983-1005.

Luca, M. (2011). 'Reviews, reputation, and revenues: the case of Yelp.com', Working Paper, Boston University.

Lucking-Reiley, D., Bryan, D., Prasad, N. and Reeves, D. (2007). 'Pennies from eBay: the determinants of price in online auctions', Journal of Industrial Economics, vol. 55(2), pp. 223-233.

McCrary, J. (2008). 'Manipulation of the running variable in the regression discontinuity design: a density test', Journal of Econometrics, vol. 142(2), pp. 698-714.

Melnik, M.I. and Alm, J. (2003). 'Does a seller's eCommerce reputation matter? Evidence from eBay auctions', The Journal of Industrial Economics, vol. 50(3), pp. 337-349.

Moretti, E. (2011). 'Social learning and peer effects in consumption: evidence from movie sales', The Review of Economic Studies, vol. 78(1), pp. 356-393.

National Restaurant Association. (2010). Restaurant Industry Operations Report, Washington, DC.

Reinstein, D.A. and Snyder, C.M. (2005). 'The influence of expert reviews on consumer demand for experience goods: a case study of movie critics', Journal of Industrial Economics, vol. 53(1), pp. 27-51.

Resnick, P., Zeckhauser, R., Swanson, J. and Lockwood, K. (2006). 'The value of reputation on eBay: a controlled experiment', Experimental Economics, vol. 9(2), pp. 79-101. 
Sorensen, A.T. (2006). 'Social learning and health plan choice', The RAND Journal of Economics, vol. 37(4), pp. 929-945.

Wang, Z. (2010). 'Anonymity, social image, and the competition for volunteers: a case study of the online market for reviews', The B.E. Journal of Economic Analysis \& Policy, vol. 10(1), article 44. 
Fig. 1: Sample Yelp.com Search Results

\section{yelp:}

bean bag coffee house IPA San Francisco

1 to 10 of 45 - Results per page: 10 :

Show Filters

\begin{tabular}{|c|c|}
\hline $\begin{array}{l}\text { 1. Bean Bag Coffee House } \\
\text { Category: Coffee \& Tea } \\
\text { Neighborhood: Western Addition/NOPA }\end{array}$ & $\begin{array}{l}\text { 601 Divisadero St } \\
\text { San Francisco, CA } 94117 \\
\text { (415) 563-3634 }\end{array}$ \\
\hline \multicolumn{2}{|c|}{$\begin{array}{l}\text { stopping at the bean bag every morning on my way to work. The bean bag coffee is NOT like that. } \\
\text { They sell coffee that tastes like roasted, fiery, burning charred blackness, the way coffee is supposed }\end{array}$} \\
\hline $\begin{array}{l}\text { 2. Mojo Bicycle Café } \\
\text { Categories: Coffee \& Tea, Bikes } \\
\text { Neighborhood: Western Addition/NOPA }\end{array}$ & $\begin{array}{l}295 \text { reviews } \\
639 \text { Divisadero St } \\
\text { San Francisco, CA } 94117 \\
\text { (415) } 440-2338\end{array}$ \\
\hline \multicolumn{2}{|c|}{$\begin{array}{l}\text { 51. Would it be too much to ask for the baristas here to know a thing or two about coffee? I have had } \\
\text { the same experience twice when trying to buy beans. It goes something like this. I pick up a bag }\end{array}$} \\
\hline $\begin{array}{l}\text { 3. 21st Amendment Brewery } \\
\text { Categories: Breweries, Pubs, American (Traditional) } \\
\text { Neighborhood: SOMA }\end{array}$ & $\begin{array}{l}563 \text { 2nd St } \\
\text { San Francisco, CA } 94107 \text { reviews } \\
\text { (415) 369-0900 }\end{array}$ \\
\hline
\end{tabular}

Been coming here regularly for a couple of years. Not too much to say except the beers are fantastic. My fave is the 21st Amendment IPA which is their house beer. The drawback is that they

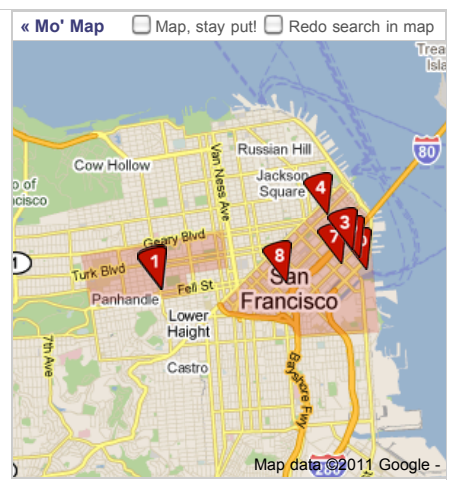

$\begin{array}{ll}\text { 4. Salt House } & \text { S4t Mission St } \\ \text { Category: American (New) } & \text { San Francisco, CA } 94104 \\ \text { Neighborhood: SOMA } & \text { (415) } 543-8900\end{array}$

(415) $543-8900$

19. Salt House is the kind of restaurant you're only going to find in Manhattan, SF or maybe Chicago. The focus is on the cuisine where it should be. Even though the decor and staff are West Coast laid

5. NOPA Category: American (New)

Neighborhood: Western Addition/NOPA tat 2218 reviews 560 Divisadero St San Francisco, CA 94117 (415) 864-8643

the right amount of meat/bread/condiments 3) Baked white bean appetizer - perfectly melded tomato and feta topped with crunchy breadcrumbs that are perfectly juxtaposed against the beans I'm a fan.

\section{Acme Burgerhaus}

Category: Burgers

Neighborhood: Western Addition/NOPA

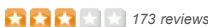

559 Divisadero St

San Francisco, CA 94117 (415) $346-3212$

The fries were crisp and had plenty of garlic on them * 1.95 draft beers. not quite as cheap as bean bag but I can't get ostrich burgers at bean bag cafe. did I mention you can eat an ostrich here? Not

7. Brickhouse Cafe Categories: American (Traditional), Breakfast \& Brunch, Bars

ABEE 585 reviews 426 Brannan St
San Francisco, CA 94107 Neighborhood: SOMA

(415) 369-0222

1- breakfast or brunch. You can't go wrong with the Vanilla Bean French Toast. Oh, oh! There's also a question of the day, and if you answer it correctly you get 25 cents off your coffee. I'm not a coffee

$\begin{array}{ll}\text { 8. Radius } & 1123 \text { Folsom St } \\ \text { Category: American (New) } & \text { San Francisco, CA } \\ \text { Neighborhood: SOMA } & \text { (415) } 525-3676\end{array}$

Neighborhood: SOMA

94103

Special Ofter

because they source everything from within a 100 miles. Obviously, exceptions are made for the coffee beans, appliances, etc. Hopefully I'Il have a chance to meet the restaurant personality of this

9. Ironside

Categories: American (New), Caterers

ARE 280 reviews

680 2nd St

San Francisco $C A 94107$ (415) 896-1127

1-f feel like they're missing a big opportunity to have smaller portions at lower prices. 3. The coffee! Ironside gets their beans from Four Barrel (delivered by bicycle messenger) so you'd expect their

10. AT\&T Park

Category: Stadiums \& Arenas

Neighborhood: SOMA

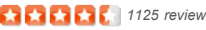

24 Willie Mays Plz

San Francisco, CA 94107

Special Offer

(415) $972-2000$

9. and out for food, lol. Every Friday, two hours before a game starts [when doors open], they offer mystery grab bags. Though it was a Saturday game.. they offered mystery grab bags but it pretty much

1 to 10 of 45 | Go to Page 12345 
Fig. 2: Reservation Availability at 7:00 pm by Average Yelp Rating
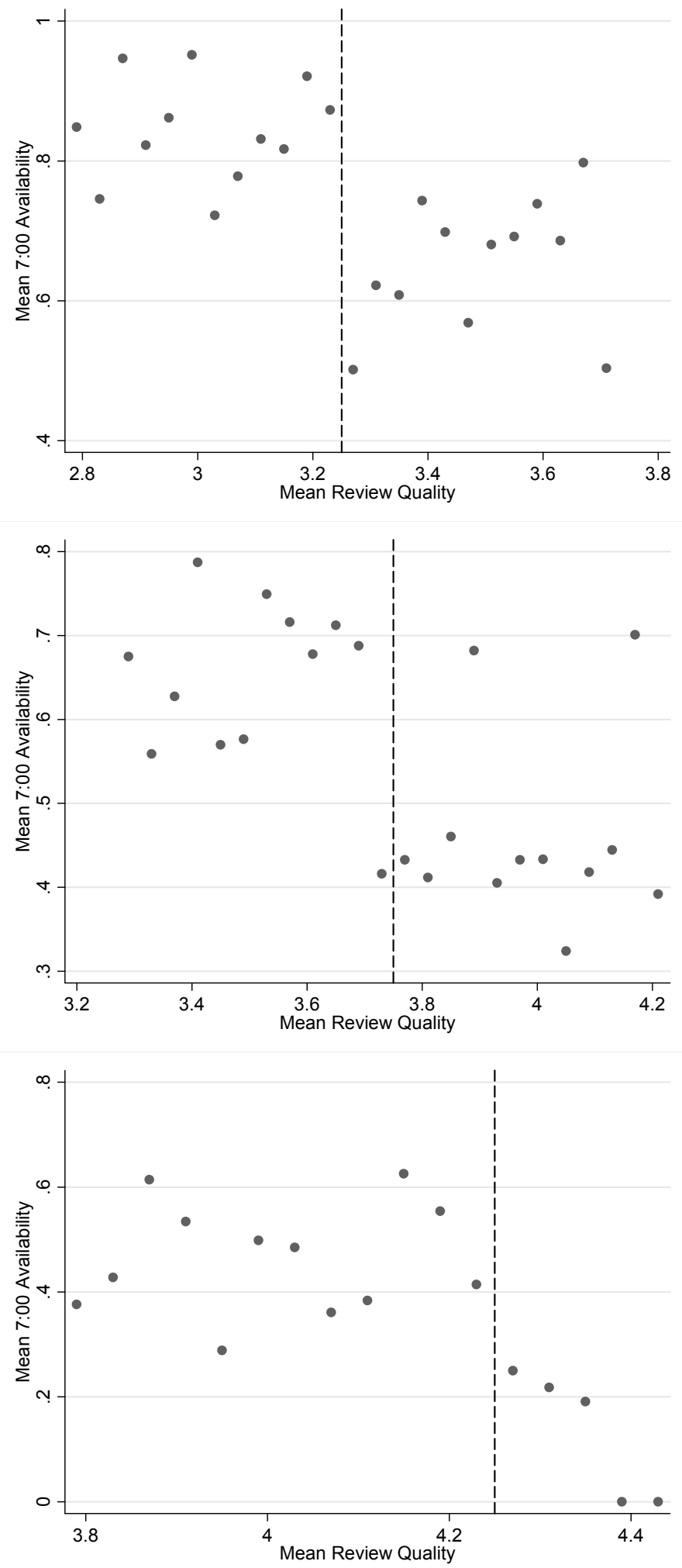
Fig. 3: Reservation Availability at 7:00 pm by Average Yelp Rating for Restaurants that Do Not Cross the Yelp Threshold

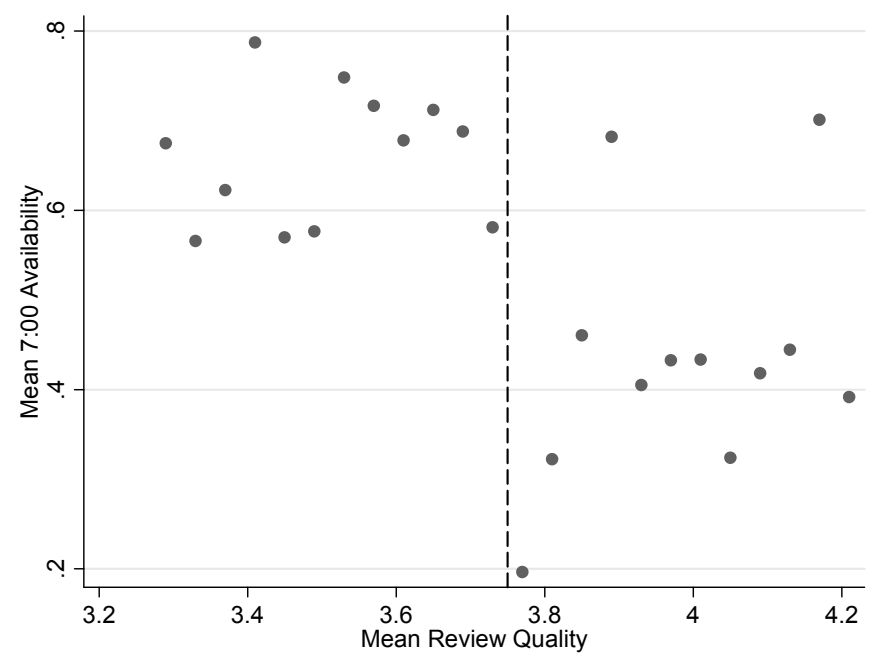

Fig. 4: Empirical Density of Restaurants

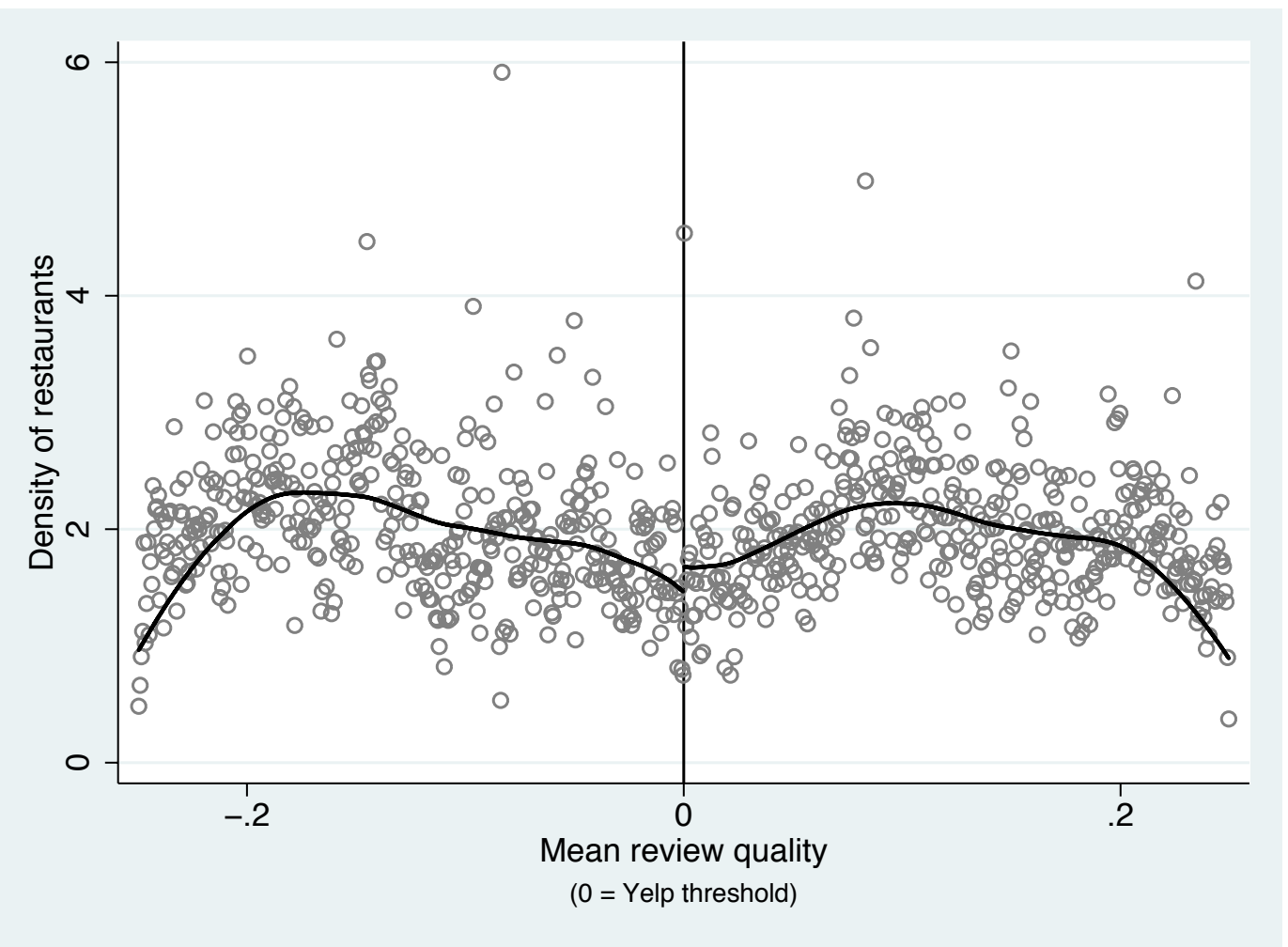


Table 1: Summary Statistics

\begin{tabular}{|c|c|c|c|c|}
\hline & \multicolumn{2}{|c|}{ All Restaurants } & \multicolumn{2}{|c|}{$\begin{array}{l}\text { Restaurants with } \\
\text { Reservation Data }\end{array}$} \\
\hline & $\begin{array}{c}\text { Mean } \\
\text { (Std Dev) }\end{array}$ & Range & $\begin{array}{c}\text { Mean } \\
(\text { Std Dev })\end{array}$ & Range \\
\hline Reviewer's Rating & $\begin{array}{c}3.69 \\
(1.13)\end{array}$ & $1-5$ & $\begin{array}{c}3.68 \\
(1.11)\end{array}$ & $1-5$ \\
\hline Reviews per Restaurant & $\begin{array}{c}167.9 \\
(248.5)\end{array}$ & $1-2,929$ & $\begin{array}{l}452.1 \\
(344.4)\end{array}$ & $28-2,236$ \\
\hline Restaurant's Average Rating & $\begin{array}{c}3.50 \\
(0.68)\end{array}$ & $1-5$ & $\begin{array}{c}3.64 \\
(0.34)\end{array}$ & $2.68-4.41$ \\
\hline $\begin{array}{l}\text { Monthly Reviews per Restaurant } \\
\text { (September 2010) }\end{array}$ & $\begin{array}{c}5.48 \\
(6.76)\end{array}$ & 0-101 & $\begin{array}{c}9.21 \\
(7.21)\end{array}$ & $1-45$ \\
\hline Restaurants & 3,953 & & 328 & \\
\hline Unique Reviews & 663,790 & & 148,281 & \\
\hline Unique Reviewers & 108,547 & & 50,409 & \\
\hline Reservation Availability at $6 \mathrm{pm}$ & & & $\begin{array}{c}0.74 \\
(0.44)\end{array}$ & \\
\hline Reservation Availability at $7 \mathrm{pm}$ & & & $\begin{array}{c}0.59 \\
(0.49)\end{array}$ & \\
\hline Reservation Availability at $8 \mathrm{pm}$ & & & $\begin{array}{c}0.68 \\
(0.47)\end{array}$ & \\
\hline
\end{tabular}


Table 2: Regression Discontinuity Results at Individual Thresholds

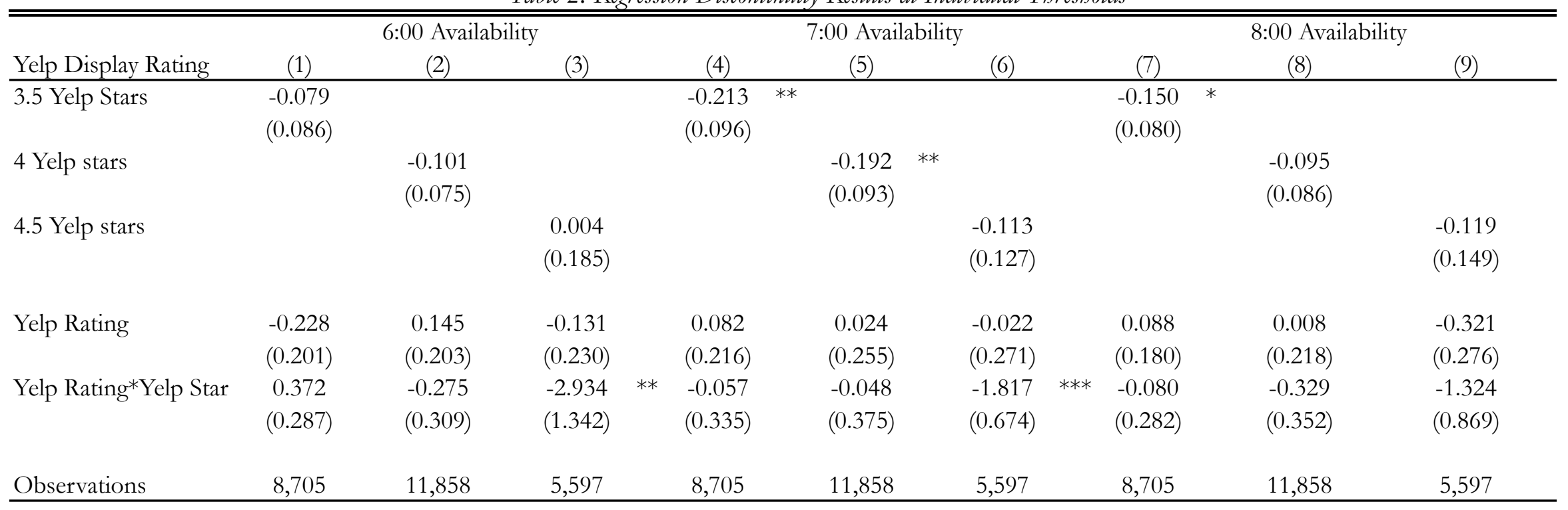

Notes 1. Contains RD estimates of the effects of an additional Yelp half-star on availability

2. Availability measures indicate whether the reservations were available at that time on Thursday, Friday, or Saturday when queried 36 hours in advance

3. Standard errors are clustered at the restaurant level

4. Stars denote significance levels: $10 \%(*), 5 \%(* *)$, and $1 \%(* * *)$ 
Table 3: Regression Discontinuity Results at Pooled Thresholds

\begin{tabular}{|c|c|c|c|c|c|c|c|}
\hline \multirow{4}{*}{ Yelp Star } & \multicolumn{7}{|c|}{ Panel A: 6:00 Availability } \\
\hline & \multicolumn{2}{|l|}{$(1)$} & $(2)$ & \multicolumn{2}{|c|}{ (3) } & $(4)$ & \multirow{2}{*}{$\frac{(5)}{0.118}$} \\
\hline & -0.117 & & $-0.224 \quad * *$ & 0.043 & & -0.181 & \\
\hline & $(0.076)$ & & $(0.089)$ & $(0.142)$ & & $(0.077)$ & $(0.180)$ \\
\hline \multirow[t]{2}{*}{ Yelp Rating } & -0.067 & & 0.227 & -0.986 & & 0.141 & -0.149 \\
\hline & $(0.350)$ & & $(0.409)$ & $(0.651)$ & & $(0.354)$ & $(0.866)$ \\
\hline \multirow[t]{2}{*}{ Yelp Rating*Yelp Star } & 0.490 & & 0.293 & 1.709 & $* *$ & 0.438 & -0.146 \\
\hline & $(0.512)$ & & $(0.630)$ & $(0.854)$ & & $(0.530)$ & $(1.136)$ \\
\hline Observations & 13,758 & & 8,641 & 4,271 & & 11,895 & 1,863 \\
\hline Sample & Full & & 100-500 Reviews & $500+$ Reviews & & Not Michelin & Michelin \\
\hline Mean 6 pm Availability & 0.745 & & 0.797 & 0.634 & & 0.794 & 0.416 \\
\hline \multirow[t]{3}{*}{ Within-Restaurant Std. Dev. In Availability } & 0.241 & & 0.211 & 0.318 & & 0.220 & 0.376 \\
\hline & \multicolumn{7}{|c|}{ Panel B: 7:00 Availability } \\
\hline & $(1)$ & & $(2)$ & (3) & & $(4)$ & $(5)$ \\
\hline \multirow[t]{2}{*}{ Yelp Star } & -0.191 & ** & -0.339 & -0.005 & & -0.272 & 0.095 \\
\hline & $(0.092)$ & & $(0.102)$ & $(0.145)$ & & $(0.094)$ & $(0.106)$ \\
\hline \multirow[t]{2}{*}{ Yelp Rating } & -0.022 & & 0.690 & -1.528 & $* *$ & 0.265 & -0.283 \\
\hline & $(0.443)$ & & $(0.472)$ & $(0.743)$ & & $(0.442)$ & $(0.640)$ \\
\hline \multirow[t]{2}{*}{ Yelp Rating*Yelp Star } & 0.526 & & -0.180 & 2.483 & ** & 0.525 & -0.569 \\
\hline & $(0.658)$ & & $(0.753)$ & $(1.039)$ & & $(0.667)$ & $(0.733)$ \\
\hline Observations & 13,758 & & 8,641 & 4,271 & & 11,895 & 1,863 \\
\hline Sample & Full & & 100-500 Reviews & $500+$ Reviews & & Not Michelin & Michelin \\
\hline Mean 7 pm Availability & 0.586 & & 0.664 & 0.412 & & 0.656 & 0.114 \\
\hline \multirow[t]{3}{*}{ Within-Restaurant Std. Dev. In Availability } & 0.219 & & 0.212 & 0.255 & & 0.223 & 0.191 \\
\hline & \multicolumn{7}{|c|}{ Panel C: 8:00 Availability } \\
\hline & $(1)$ & & $(2)$ & (3) & & $(4)$ & $(5)$ \\
\hline \multirow[t]{2}{*}{ Yelp Star } & -0.145 & $*$ & -0.210 & -0.059 & & -0.237 & 0.205 \\
\hline & $(0.084)$ & & $(0.101)$ & $(0.156)$ & & $(0.082)$ & $(0.138)$ \\
\hline \multirow[t]{2}{*}{ Yelp Rating } & -0.108 & & -0.034 & -0.761 & & 0.226 & -0.662 \\
\hline & $(0.389)$ & & $(0.457)$ & $(0.753)$ & & $(0.359)$ & $(0.765)$ \\
\hline \multirow[t]{2}{*}{ Yelp Rating*Yelp Star } & 0.794 & & 0.790 & 1.704 & & 0.766 & -0.109 \\
\hline & $(0.590)$ & & $(0.686)$ & $(1.061)$ & & $(0.557)$ & $(1.049)$ \\
\hline Observations & 13,758 & & 8,641 & 4,271 & & 11,895 & 1,863 \\
\hline Sample & Full & & 100-500 Reviews & $500+$ Reviews & & Not Michelin & Michelin \\
\hline Mean 8 pm Availability & 0.682 & & 0.756 & 0.521 & & 0.754 & 0.202 \\
\hline Within-Restaurant Std. Dev. In Availability & 0.226 & & 0.205 & 0.296 & & 0.222 & 0.257 \\
\hline
\end{tabular}

Notes 1. Contains RD estimates of the effects of an additional Yelp half-star on availability

2. Availability measures indicate whether the reservations were available at that time on Thursday, Friday, or Saturday when queried 36 hours in advance

3. Michelin sample includes restaurant which received a Michelin star in 2009 or 2010 and restaurants listed on the San Francisco Chronicle's Top 100

4. All regressions have a bandwidth of 0.25 stars

5. Standard errors are clustered at the restaurant level

6. Stars denote significance levels: $10 \%\left(^{*}\right), 5 \%\left(^{* *}\right)$, and $1 \%(* * *)$ 
Table 4: Dynamic Aspects of Average Yelp Ratings

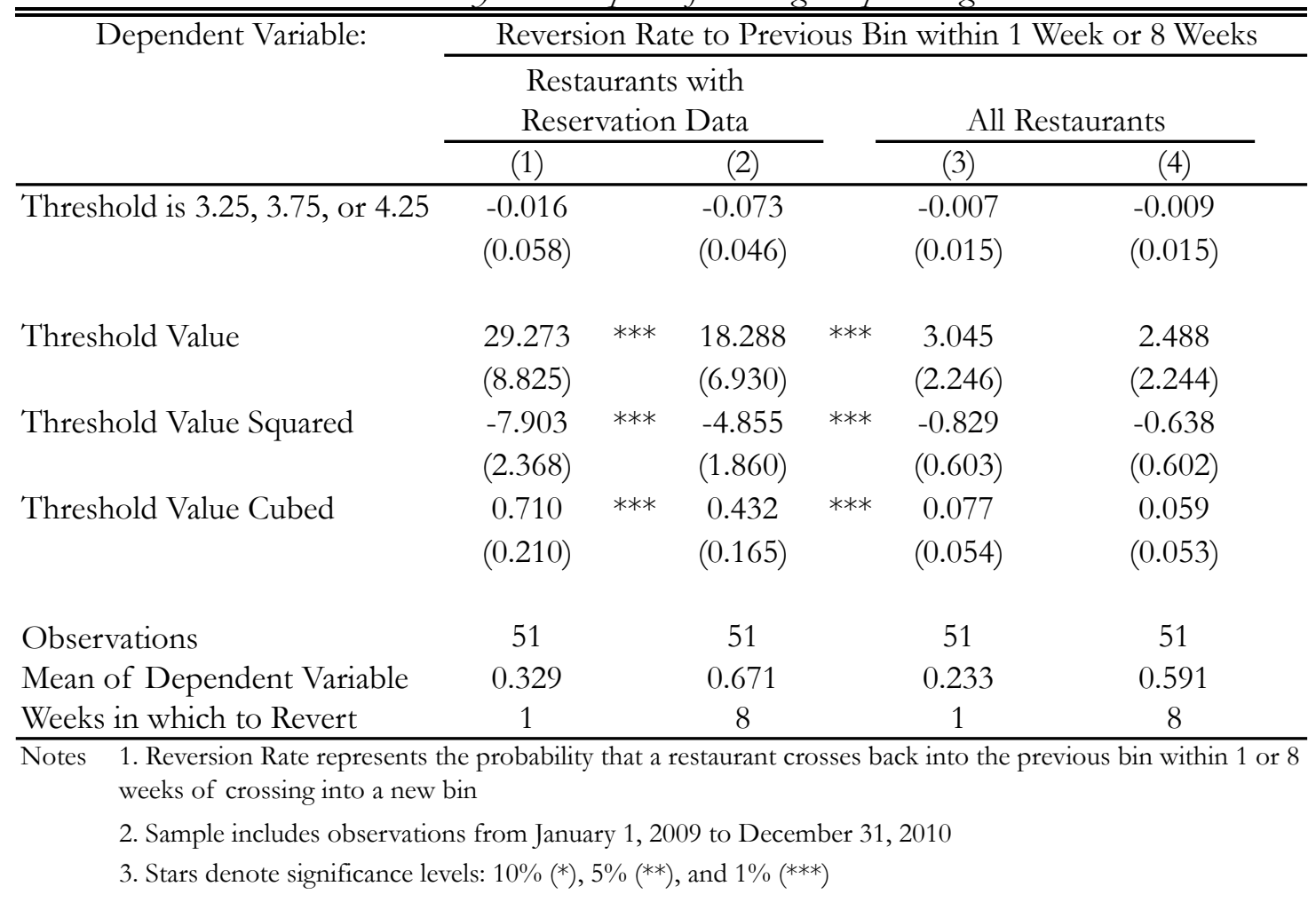


Table 5: Tests for RD Gaming - Breaks in Density and Reviewer Characteristics

\begin{tabular}{|c|c|c|c|c|c|c|c|}
\hline \multirow[t]{3}{*}{ Dependent Variable: } & Density & $\begin{array}{c}\% \text { of Reviews } \\
\text { with } 5 \text { Stars }\end{array}$ & $\begin{array}{c}\text { Std Dev of } \\
\text { Ratings }\end{array}$ & $\begin{array}{l}\text { Avg Reviews } \\
\text { per Reviewer }\end{array}$ & $\begin{array}{c}\% \text { of Reviewers } \\
\text { with } 1 \text { Review }\end{array}$ & $\begin{array}{c}\% \text { of Reviewers } \\
\text { with }<6 \text { Reviews }\end{array}$ & $\begin{array}{c}\text { Own Rating - Avg } \\
\text { Rating of Other } \\
\text { Restaurants }\end{array}$ \\
\hline & \multicolumn{7}{|c|}{ Panel A: Restaurants with Reservations Data } \\
\hline & $(1)$ & $(2)$ & (3) & (4) & $(5)$ & $(6)$ & $(7)$ \\
\hline \multirow[t]{2}{*}{ Yelp Star } & 0.137 & 0.004 & 0.001 & -6.27 & 0.0004 & -0.0022 & 0.022 \\
\hline & $(0.144)$ & $(0.008)$ & $(0.015)$ & $(5.47)$ & $(0.0013)$ & $(0.0048)$ & $(0.023)$ \\
\hline Observations & 834 & 230,880 & 230,880 & 230,880 & 230,880 & 230,880 & 230,880 \\
\hline \multirow[t]{3}{*}{ Mean of Dependent Variable } & 1.911 & 0.244 & 1.055 & 180.66 & 0.0095 & 0.0631 & -0.056 \\
\hline & \multicolumn{7}{|c|}{ Panel B: Restaurants with 100 to 500 Reviews } \\
\hline & $(1)$ & $(2)$ & (3) & (4) & $(5)$ & $(6)$ & $(7)$ \\
\hline Yelp Star & 0.110 & 0.008 & 0.006 & -5.43 & 0.0000 & -0.0031 & 0.003 \\
\hline & $(0.147)$ & $(0.012)$ & $(0.020)$ & $(6.85)$ & $(0.0017)$ & $(0.0058)$ & $(0.029)$ \\
\hline Observations & 626 & 131,315 & 131,315 & 131,315 & 131,315 & 131,315 & 131,315 \\
\hline \multirow[t]{3}{*}{ Mean of Dependent Variable } & 1.912 & 0.236 & 1.064 & 182.04 & 0.0097 & 0.0653 & -0.087 \\
\hline & \multicolumn{7}{|c|}{ Panel C: All Restaurants } \\
\hline & $(1)$ & $(2)$ & (3) & (4) & $(5)$ & $(6)$ & $(7)$ \\
\hline Yelp Star & 0.063 & -0.004 & 0.007 & 3.98 & 0.0001 & -0.0022 & 0.002 \\
\hline & $(0.055)$ & $(0.003)$ & $(0.006)$ & $(2.94)$ & $(0.0006)$ & $(0.0019)$ & $(0.013)$ \\
\hline Observations & 2,274 & $1,716,949$ & $1,716,949$ & $1,716,949$ & $1,716,949$ & $1,716,949$ & $1,713,678$ \\
\hline Mean of Dependent Variable & 1.888 & 0.244 & 1.036 & 199.33 & 0.0087 & 0.0570 & -0.014 \\
\hline
\end{tabular}

Notes 1. Contains RD estimates of the effects of an additional Yelp half-star on dependent variable

2. Restaurants with 100 to 500 Reviews sample contains restaurants that have reservations data and have between 100 to 500 total reviews

3. All samples include observations from January 1, 2009 to December 31, 2010

4. Standard errors are clustered at the restaurant level

5. Standard errors in column (1) are cluster bootstrapped at the restaurant level

6. Stars denote significance levels: $10 \%(*), 5 \%(* *)$, and $1 \%\left({ }^{* *}\right)$ 
Table 6: Tests for RD Gaming - Speed of Change in Average Rating Near Threshold

\begin{tabular}{|c|c|c|c|c|c|c|c|c|c|c|c|}
\hline \multirow[t]{3}{*}{ Dependent Variable: } & \multicolumn{11}{|c|}{ Reached Next Rating Bin within 1 Week or 8 Weeks } \\
\hline & \multicolumn{3}{|c|}{$\begin{array}{l}\text { Restaurants with } \\
\text { Reservation Data }\end{array}$} & \multicolumn{5}{|c|}{$\begin{array}{c}\text { Restaurants with } 100 \text { to } 500 \\
\text { Reviews }\end{array}$} & \multicolumn{3}{|c|}{ All Restaurants } \\
\hline & $(1)$ & & $(2)$ & & (3) & & (4) & & (5) & & $(6)$ \\
\hline Initial Rating Bin is $3.22,3.72$, or 4.22 & $\begin{array}{l}-0.011 \\
(0.040)\end{array}$ & & $\begin{array}{l}-0.039 \\
(0.061)\end{array}$ & & $\begin{array}{l}-0.005 \\
(0.017)\end{array}$ & & $\begin{array}{l}-0.008 \\
(0.055)\end{array}$ & & $\begin{array}{c}0.021 \\
(0.013)\end{array}$ & & $\begin{array}{c}0.025 \\
(0.018)\end{array}$ \\
\hline Initial Rating Bin & $\begin{array}{r}-18.230 \\
(6.074)\end{array}$ & $* * *$ & $\begin{array}{l}-25.368 \\
(9.248)\end{array}$ & $* * *$ & $\begin{array}{l}-8.467 \\
(2.680)\end{array}$ & $* * *$ & $\begin{array}{l}-17.358 \\
(8.840)\end{array}$ & $*$ & $\begin{array}{l}-8.445 \\
(1.952)\end{array}$ & $* * *$ & $\begin{array}{l}-5.343 \\
(2.774)\end{array}$ \\
\hline Initial Rating Bin Squared & $\begin{array}{c}4.779 \\
(1.630)\end{array}$ & $* * *$ & $\begin{array}{c}6.668 \\
(2.482)\end{array}$ & $* * *$ & $\begin{array}{c}2.190 \\
(0.722)\end{array}$ & $* * *$ & $\begin{array}{l}4.481 \\
(2.381)\end{array}$ & $*$ & $\begin{array}{c}2.137 \\
(0.524)\end{array}$ & $* * *$ & $\begin{array}{r}1.249 \\
(0.744)\end{array}$ \\
\hline Initial Rating Bin Cubed & $\begin{array}{l}-0.415 \\
(0.145)\end{array}$ & $* * *$ & $\begin{array}{l}-0.584 \\
(0.220)\end{array}$ & $* * *$ & $\begin{array}{l}-0.188 \\
(0.064)\end{array}$ & $* * *$ & $\begin{array}{l}-0.388 \\
(0.212)\end{array}$ & $*$ & $\begin{array}{l}-0.181 \\
(0.047)\end{array}$ & $* * *$ & $\begin{array}{l}-0.098 \\
(0.066)\end{array}$ \\
\hline Observations & 51 & & 51 & & 50 & & 50 & & 51 & & 51 \\
\hline Mean of Dependent Variable & 0.124 & & 0.295 & & 0.023 & & 0.176 & & 0.134 & & 0.345 \\
\hline Weeks after entering Initial Rating Bin & 1 & & 8 & & 1 & & 8 & & 1 & & 8 \\
\hline
\end{tabular}

Notes 1. Reached Next Rating Bin represents the probability that a restaurant crosses into the next rating bin within 1 or 8 weeks of crossing into a given bin 2. Sample includes observations from January 1, 2009 to December 31, 2010

3. Stars denote significance levels: $10 \%(*), 5 \%(* *)$, and $1 \%(* *)$ 
Table 7: Effect of Yelp Star on Yelp Listing Order

\begin{tabular}{|c|c|c|c|c|c|c|}
\hline \multirow[t]{3}{*}{ Dependent Variable: } & \multicolumn{6}{|c|}{ Yelp Listing Order } \\
\hline & \multicolumn{2}{|c|}{$\begin{array}{l}\text { Restaurants with } \\
\text { Reservation Data }\end{array}$} & \multicolumn{3}{|c|}{ All Restaurants } & \\
\hline & $(1)$ & (2) & & (3) & (4) & \\
\hline \multirow[t]{2}{*}{ Yelp Star } & 42.1 & -15.9 & & -4.1 & -5.0 & \\
\hline & $(37.4)$ & (32.1) & & $(16.4)$ & $(15.2)$ & \\
\hline \multirow[t]{2}{*}{ Yelp Rating } & -154.5 & -122.2 & & 158.4 & -100.7 & \\
\hline & $(184.3)$ & $(156.2)$ & & (78.1) & (72.4) & \\
\hline \multirow[t]{2}{*}{ Yelp Rating*Yelp Star } & 177.8 & 202.7 & & -141.7 & -124.9 & \\
\hline & $(252.5)$ & $(213.9)$ & & $(113.7)$ & $(105.5)$ & \\
\hline \multirow[t]{2}{*}{ Rank by Yelp Rating } & & -5.952 & $* * *$ & & -1.031 & *** \\
\hline & & $(0.553)$ & & & $(0.004)$ & \\
\hline Observations & 297 & 297 & & 2,266 & 2,266 & \\
\hline Mean of Dependent Variable & $1,458.8$ & $1,458.8$ & & $1,459.0$ & $1,459.0$ & \\
\hline
\end{tabular}

Notes 1. Contains RD estimates of the effects of an additional Yelp half-star on Yelp lising order 2. Rank by Yelp Rating represents a restaurant's rank according to its average Yelp rating

3. Yelp listing order was measured on January 3, 2011

4. Stars denote significance levels: $10 \%(*), 5 \%(* *)$, and $1 \%(* *)$ 
Table 8: Effect of Yelp Star on Restaurant Wait Times

\begin{tabular}{|c|c|c|c|c|c|c|c|c|c|}
\hline \multirow[t]{2}{*}{ Dependent Variable: } & \multicolumn{3}{|c|}{$\begin{array}{l}\text { Minutes of Wait Time } \\
\text { (Top-coded) }\end{array}$} & & \multicolumn{3}{|c|}{ Minutes of Wait Time } & & \multirow{2}{*}{$\frac{\text { Any Wait }}{(5)}$} \\
\hline & $(1)$ & & $(2)$ & & (3) & & $(4)$ & & \\
\hline \multirow[t]{2}{*}{ Yelp Star } & 26.9 & ** & 131.4 & * & 49.1 & * & 120.8 & ** & 0.44 \\
\hline & $(12.4)$ & & $(78.4)$ & & $(25.2)$ & & $(56.1)$ & & $(0.28)$ \\
\hline \multirow[t]{2}{*}{ Yelp Rating } & -151.7 & * & -622.9 & & -198.2 & * & -487.2 & * & -1.97 \\
\hline & $(75.6)$ & & $(404.1)$ & & (111.9) & & $(278.3)$ & & $(1.65)$ \\
\hline \multirow[t]{2}{*}{ Yelp Rating*Yelp Star } & 61.0 & & 53.7 & & 13.4 & & -69.0 & & -0.52 \\
\hline & $(116.7)$ & & $(580.6)$ & & $(216.5)$ & & $(487.7)$ & & 2.37 \\
\hline Estimation Model & OLS & & Tobit & & OLS & & Tobit & & OLS \\
\hline Observations & 63 & & 63 & & 63 & & 63 & & 63 \\
\hline Mean of Dependent Variable & 14.2 & & 14.2 & & 20.4 & & 20.4 & & 0.33 \\
\hline
\end{tabular}

Notes 1. Contains RD estimates of the effects of an additional Yelp half-star on wait time

2. Top-coded Wait Time is top-coded at 60 minutes

3. Standard errors are clustered at the restaurant level

4. Stars denote significance levels: $10 \%(*), 5 \%(* *)$, and $1 \%(* *)$ 
Table 9: Effect of Yelp Star on External Measures of Quality

\begin{tabular}{lccccc}
\hline \hline & $(1)$ & $(2)$ & $(3)$ & $(4)$ & $(5)$ \\
Dependent Variable: & Food & Décor & Service & Cost & Rating \\
\hline Yelp Star & -0.122 & 0.481 & 0.204 & -3.924 & 0.039 \\
& $(0.773)$ & $(0.885)$ & $(0.731)$ & $(4.846)$ & $(0.062)$ \\
Yelp Rating & & & & & \\
& 3.208 & -2.834 & 1.209 & 3.419 & -0.108 \\
Yelp Rating*Yelp Star & $(3.759)$ & $(4.411)$ & $(3.690)$ & $(25.725)$ & $(0.291)$ \\
& -5.255 & 0.381 & -0.796 & 9.329 & 0.303 \\
& $(5.153)$ & $(6.273)$ & $(5.096)$ & $(30.644)$ & $(0.431)$ \\
Observations & & & & & 13,360 \\
Source & 9,506 & 9,506 & 9,506 & 9,355 & Reservation \\
& Zagat & Zagat & Zagat & Zagat & Database \\
Mean of Dependent Variable & 21.78 & 19.78 & 20.56 & 46.03 & 3.90 \\
Bandwidth & 0.25 & 0.25 & 0.25 & 0.25 & 0.25 \\
\hline
\end{tabular}

Notes 1. Contains RD estimates of the effects of an additional Yelp half-star on dependent variable 2. Standard errors are clustered at the restaurant level

3. Stars denote significance levels: $10 \%(*), 5 \%(* *)$, and $1 \%(* * *)$ 


\section{APPENdiX: Modeling MANipUlation OF Yelp REVIEWS}

We know little about the technology by which restaurateurs can manipulate their scores. In principle, one can imagine manipulation behavior driven by both short-run and long-run considerations. In the short run, a restaurateur may have more sway over his average review quality as he faces fewer competing legitimate reviews. On the other hand, restaurants are presumably primarily interested in their long-run profits, and there may be some scarcity in the resources (both time and otherwise) that a restaurateur uses to successfully leave fraudulent reviews. Here, we begin with a static framework meant to consider medium to long run behavior and then incorporate it into a dynamic framework to see what sorts of behavior could lead to manipulation discontinuities at the threshold.

We propose the following framework to consider this problem. First, suppose a restaurateur is deciding how many fake reviews to leave for his restaurant. Currently, his restaurant has an average rating $q$ based on $r$ reviews. If he leaves $n$ reviews, fraction $p(n)$ are interpreted by Yelp as true reviews; $p(n)$ is decreasing in $n$ and represents the probability that a review makes it through Yelp's filter. Naturally, each fraudulent review receives 5 stars, and costs him $c$ in effort. ${ }^{30}$ Confounding his efforts is that Yelp patrons also leave $h$ reviews with mean quality $q^{\prime}$, where $q^{\prime}$ is randomly distributed with $\operatorname{cdf} F\left(q^{\prime}\right)$. For simplicity we treat $h$ as fixed in the static model, but treating it as random does not affect our conclusions. ${ }^{31}$ After leaving his own reviews and accumulating his new reviews from Yelp patrons, the restaurant is left with mean review quality

$$
\hat{q}=\frac{r q+h q^{\prime}+5 n p(n)}{r+h+n p(n)}
$$

A higher Yelp rating renders the restaurant more profitable. Focusing on a single threshold, suppose that the restaurant earns $\pi$ in additional profits if $\hat{q}>\bar{q}$. In a static model like this one, these additional profits can be viewed as the present value of the future

\footnotetext{
${ }^{30}$ One may also imagine that $c$ is increasing in $n$. In practice, if either $c$ or $p(n)$ is increasing in $n$ then the model achieves similar predictions.

31 If $h$ is random, the marginal benefit expression we derive in equation (6) becomes a sum of the same expression over all points of support of $h$, with each term weighted by the probability that $h$ equals the summation index value.
} 
stream of payoffs from having the higher expected displayed rating. His decision problem then is to

$$
\max _{n} \pi P(\hat{q}>\bar{q})-c n
$$

or

$$
\max _{n} \pi\left[1-F\left(\frac{\bar{q}(r+h+n p(n))-5 n p(n)-r q}{h}\right)\right]-c n
$$

The marginal cost of leaving each additional review, $c$, is constant. Therefore, the incentive to game will change discontinuously at the threshold $\bar{q}$ if the marginal benefit of an additional fake review is discontinuously higher below the threshold than above. Note that the marginal benefit is given by

$$
(5-\bar{q})\left[\frac{p(n)+n p^{\prime}(n)}{h}\right] f\left(\frac{\bar{q}(r+h+n p(n))-5 n p(n)-r q}{h}\right)
$$

Suppose $n^{*}$ solves this problem for restaurateurs with average ratings just above the threshold. For restaurateurs with average ratings just below the threshold to leave discontinuously more fake reviews than restaurateurs just above the threshold, it would need to be the case that $\bar{q}-\frac{(5-\bar{q}) n^{*} p\left(n^{*}\right)}{h}$ is a point of discontinuity of $f(\cdot)$. In other words, for there to be a rational incentive to manipulate Yelp scores which would change systematically and discontinuously at the threshold, it would have to be the case that the probability density of mean incoming review quality changes sharply at a specific point that lies somewhere below the threshold.

In the medium to long run, $h$ is large, and the Central Limit Theorem implies that $f(\cdot)$ is approximately normal, ruling out the possibility of discontinuous payoffs. Thus, if restaurateurs are leaving false reviews only occasionally with the hope of providing increased profits for several periods, we can conclude that there are no discontinuous incentives to manipulate at the threshold. In the very short run, however, the incoming mean quality of reviews is lumpy and affected by the discreteness of $h$. In particular, incoming mean review quality is likely to take on integers or fractions with small denominators. Thus, if our static model is meant to represent sufficiently short-run behavior, it cannot rule out discontinuous 
manipulation. This could be particularly relevant if restaurateurs who manipulate Yelp both condition their manipulation behavior on their current Yelp ratings and have the capability to leave fake reviews consistently and with great frequency.

To test whether discontinuous manipulation is reasonable in a short-run, highly manipulable world, we simulate a dynamic version of this model. In particular, we suppose that each period, restaurants choose to leave a false review or not, which passes through Yelp's filter with certainty; that each period, they receive $h$ legitimate reviews with $E[h]>0$, and that they choose their manipulation strategies to maximise the present discounted value of expected profit streams.

To be conservative, we impose the following restriction on the strategy space: manipulators are allowed only to adopt a strategy of the form "enter a fake review if display ratings are less than $\overline{\bar{q}}$ " for some $\overline{\bar{q}}$. This type of strategy seems most likely to create a discontinuity in manipulation behavior at a specific threshold, and it rules out behavior where restaurateurs front-load their manipulations. Given that false reviews are assets which do not depreciate and which have the greatest effect on ratings when total reviews are low, this choice rules out reasonable strategies where a restaurateur concentrates his efforts on leaving many fraudulent reviews early on in a way unrelated to his proximity to Yelp thresholds. Since a front-loaded strategy would weaken the contemporaneous relationship between a restaurant's average rating and its manipulation behavior, this choice is conservative. We further suppose that Yelp's filter allows the restaurant to leave exactly one false review per period. ${ }^{32}$ When $E[h]$ is small, suggesting that the period is short, this allows restaurants to have strong control over their displayed rating. Finally, we assume that the expected value of entering reviews $E\left[q^{\prime}\right]$ evolves over time at a rate calibrated to the observed levels in Yelp (a typical restaurant experiences an average change of 0.04 Yelp points in its rating each year). To test whether gaming behavior can result in density jumps at the threshold, we focus on the 3.25 threshold. We allow 6 restaurants to enter our simulation with average ratings that range from 3.0 to 3.5 in evenly spaced tenths. Each restaurant begins with 200 preexisting reviews and receives an average of 1.7 new reviews per week, the

\footnotetext{
32 The potential for Yelp's filter to catch fake reviews may be increasing in the total number of fraudulent reviews, rather than the concurrent number. This possibility, however, renders gaming even less likely to vary strongly at the threshold, because the cost of gaming increases over time. In the long run, the restaurant gives up gaming altogether. In the short to medium run, the restaurant's optimal gaming threshold is likely to change over time, making it unlikely that manipulators pile up at specific average ratings.
} 
approximate medians of the respective empirical distributions. For each restaurant we consider every strategy with a gaming threshold between $\overline{\bar{q}}=3.00$ and $\overline{\bar{q}}=4.00$ and we run 400 simulations per strategy. Each simulation follows a single restaurant that implements a single strategy over 10 years. To explore whether gaming can create a discontinuous jump in density, we plot the empirical distributions of those restaurants after two years of gaming (the approximate point at which we observe restaurants in our estimation sample).

We find the following. If restaurateurs choose to game whenever their average rating crosses below the 3.25 threshold, there is indeed a large jump in density exactly at the threshold, demonstrated by the solid line in Figure A1. This suggests that it is possible for gaming to generate a discontinuous jump in density at the threshold. However, this behavior is suboptimal. The three other density lines in Figure A1 show what happens when the restaurant behaves optimally given several assumptions on $\pi$, the return to being above a Yelp threshold. ${ }^{33}$ Recall that the motivation for this test was that gaming benefits may greatly outweigh costs; the interpretation here of each level of $\pi$ is of the ratio of weekly profits from an extra half star to the costs of leaving a false review. If $\pi$ is two, represented by the dashed-density, there is a large probability mass of optimally-behaving review manipulators. However, it is notably to the right of the 3.25 Yelp threshold, as these restaurateurs find it worthwhile to maintain a buffer between their current rating and the threshold. When $\pi$ is larger than two, there is no noticeable density jump across the range. This occurs because restaurants choose to game nearly all the time if the net benefits of gaming are high enough. This trend is not broken by allowing heterogeneity in initial review levels or review arrival rates, which tends to further smooth out the posterior distribution of average review scores. $^{34}$

From these simulations, we draw several conclusions. First, if the returns to gaming are high, savvy restaurateurs will choose to game. Second, it is possible for restaurateurs to manipulate their ratings in a way that creates a discontinuous jump in gaming at the

\footnotetext{
${ }^{33}$ We normalise $c$ to be 1 in each of these simulations. Simple calibrations presented in Section 5 suggest that the return to crossing a Yelp threshold is in the range of several hundred dollars per week. Thus $\pi$ is likely to substantially exceed 1 if the cost of leaving a fake review is less than $\$ 100$.

${ }^{34}$ Heterogeneity in initial number of reviews does create interesting heterogeneity in the optimal gaming behavior. Restaurants with few entering reviews find gaming worthwhile at almost any initial rating even for very low levels of $\pi$, while restaurants with large numbers of entering reviews need higher levels of $\pi$ to find gaming worthwhile at all. Given that the true data represent an average of restaurants with different numbers of current ratings, this suggests that the true distribution of gamers is even smoother if gamers are behaving optimally, as it represents an average of a variety of gaming behaviors.
} 
threshold, and as such we need to test for this behavior. However, this behavior only exists under strong assumptions: restaurateurs must be able to leave a great number of false reviews (and update them continuously over time) and restaurateurs must be behaving suboptimally (even among a class of naïve and discontinuous strategies). ${ }^{35}$ Thus, while it is very likely that some restaurateurs leave substantial numbers of fake reviews, it is not at all obvious that there should be a discontinuous change in manipulation at the threshold. This conclusion previews the empirical results in the next section.

35 The incentive to manipulate ratings changes sharply at Yelp thresholds only when restaurants have a very high degree of control over their average ratings (i.e., they can leave many fake reviews for every true review). In this case, however, they have no incentive to stop manipulating until they reach the 5-star threshold. Since all of our significant results are at the 3.5-star and 4-star thresholds, this type of extreme manipulation behavior could not explain our results. 


\section{APPENDIX FIgURES AND TABLES}

Fig. A1: Simulated Density of Restaurants by Manipulation Strategy

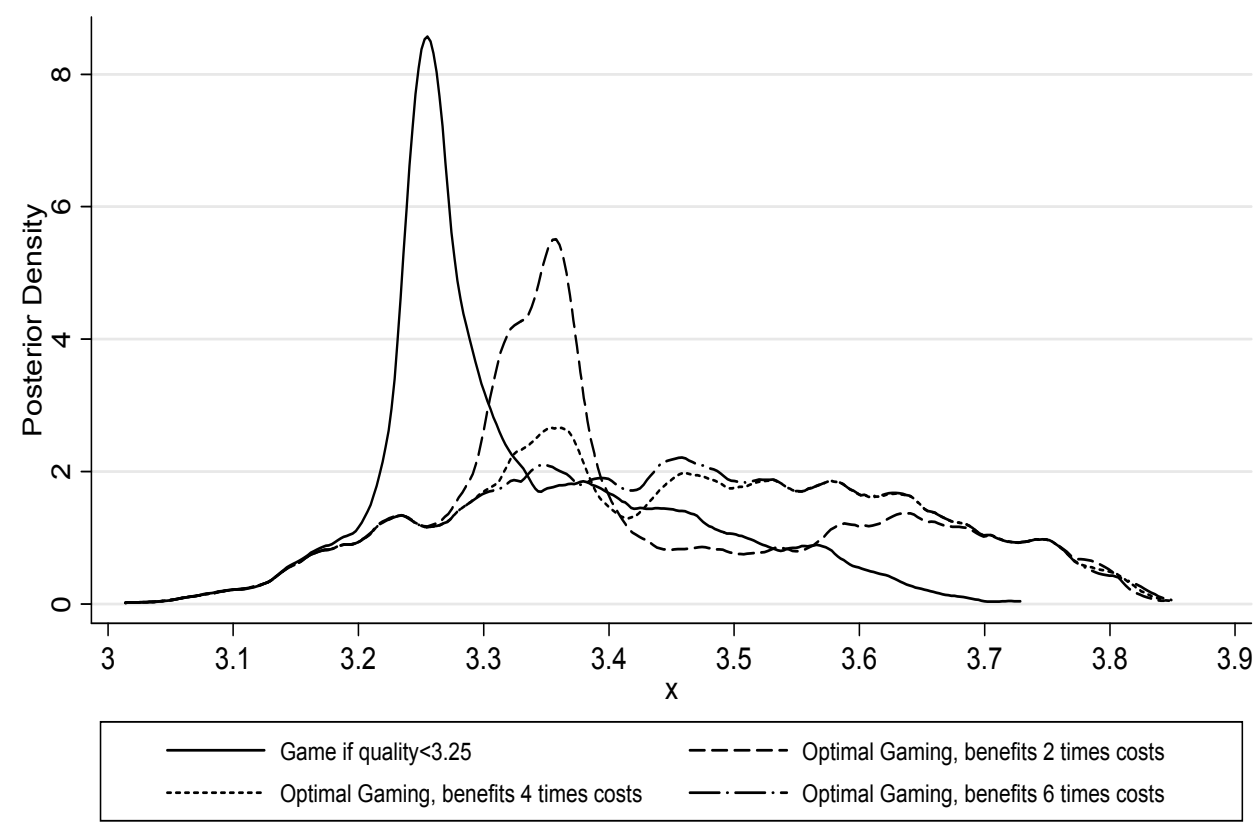




\begin{tabular}{|c|c|c|c|c|c|c|c|}
\hline \multirow[t]{2}{*}{ Dependent Variable: } & Density & $\begin{array}{c}\% \text { of Reviews } \\
\text { with } 5 \text { Stars }\end{array}$ & $\begin{array}{l}\text { Avg Reviews } \\
\text { per Reviewer }\end{array}$ & $\begin{array}{l}\text { Avg Reviews } \\
\text { per Reviewer }\end{array}$ & $\begin{array}{c}\% \text { of Reviewers } \\
\text { with } 1 \text { Review }\end{array}$ & $\begin{array}{c}\% \text { of Reviewers } \\
\text { with }<6 \text { Reviews }\end{array}$ & $\begin{array}{c}\text { Own Rating - Avg } \\
\text { Rating of Other } \\
\text { Restaurants }\end{array}$ \\
\hline & $(1)$ & $(2)$ & (3) & $(4)$ & (5) & (6) & $(7)$ \\
\hline \multirow[t]{2}{*}{ Yelp Star } & -0.386 & -0.006 & -0.017 & -7.36 & 0.0015 & -0.0028 & 0.022 \\
\hline & $(0.407)$ & $(0.011)$ & $(0.021)$ & $(6.86)$ & $(0.0019)$ & $(0.0074)$ & $(0.031)$ \\
\hline Observations & 310 & 31,657 & 31,657 & 31,657 & 31,657 & 31,657 & 31,657 \\
\hline Mean of Dependent Variable & 1.895 & 0.246 & 1.063 & 169.03 & 0.0112 & 0.0723 & -0.057 \\
\hline
\end{tabular}

Notes 1. Contains RD estimates of the effects of an additional Yelp half-star on dependent variable

2. Sample is limited to restaurants and dates for which we have reservations data

3. Standard errors are clustered at the restaurant level

4. Standard errors in column (1) are cluster bootstrapped at the restaurant level

5. Stars denote significance levels: $10 \%(*), 5 \%(* *)$, and $1 \%(* *)$ 
Table A2: Tests for RD Gaming - Breaks in Density and Reviewer Characteristics at Individual Thresholds

\begin{tabular}{|c|c|c|c|c|c|c|c|}
\hline \multirow[t]{3}{*}{ Dependent Variable: } & Density & $\begin{array}{c}\% \text { of Reviews } \\
\text { with } 5 \text { Stars }\end{array}$ & $\begin{array}{c}\text { Std Dev of } \\
\text { Ratings }\end{array}$ & $\begin{array}{l}\text { Avg Reviews } \\
\text { per Reviewer }\end{array}$ & $\begin{array}{c}\% \text { of Reviewers } \\
\text { with } 1 \text { Review }\end{array}$ & $\begin{array}{c}\% \text { of Reviewers } \\
\text { with }<6 \text { Reviews }\end{array}$ & $\begin{array}{c}\text { Own Rating - Avg } \\
\text { Rating of Other } \\
\text { Restaurants }\end{array}$ \\
\hline & \multicolumn{7}{|c|}{ Panel A: 3.25 Yelp Threshold } \\
\hline & $(1)$ & $(2)$ & $(3)$ & (4) & $(5)$ & $(6)$ & $(7)$ \\
\hline \multirow[t]{2}{*}{ 3.5 Yelp Stars } & -0.143 & -0.010 & 0.002 & -8.03 & 0.0003 & -0.0001 & 0.013 \\
\hline & $(0.499)$ & $(0.012)$ & $(0.033)$ & $(8.79)$ & $(0.0022)$ & $(0.0085)$ & $(0.053)$ \\
\hline Observations & 853 & 146,942 & 146,942 & 146,942 & 146,942 & 146,942 & 146,791 \\
\hline \multirow[t]{3}{*}{ Mean of Dependent Variable } & 0.952 & 0.167 & 1.114 & 189.23 & 0.0099 & 0.0630 & -0.294 \\
\hline & \multicolumn{7}{|c|}{ Panel B: 3.75 Yelp Threshold } \\
\hline & $(1)$ & $(2)$ & $(3)$ & (4) & $(5)$ & $(6)$ & $(7)$ \\
\hline \multirow[t]{2}{*}{4 Yelp Stars } & 0.112 & -0.006 & -0.012 & -4.29 & -0.0010 & -0.0045 & -0.019 \\
\hline & $(0.213)$ & $(0.008)$ & $(0.015)$ & $(5.90)$ & $(0.0014)$ & $(0.0054)$ & $(0.027)$ \\
\hline Observations & 892 & 200,578 & 200,578 & 200,578 & 200,578 & 200,578 & 200,578 \\
\hline \multirow[t]{3}{*}{ Mean of Dependent Variable } & 0.978 & 0.242 & 1.050 & 180.92 & 0.0091 & 0.0623 & -0.032 \\
\hline & \multicolumn{7}{|c|}{ Panel C: 4.25 Yelp Threshold } \\
\hline & $(1)$ & $(2)$ & (3) & (4) & $(5)$ & $(6)$ & $(7)$ \\
\hline \multirow[t]{2}{*}{ 4.5 Yelp Stars } & -0.530 & 0.028 & 0.031 & -2.73 & -0.0006 & 0.0011 & 0.067 \\
\hline & $(0.580)$ & $(0.018)$ & $(0.034)$ & $(9.71)$ & $(0.0040)$ & $(0.0125)$ & $(0.045)$ \\
\hline Observations & 630 & 92,780 & 92,780 & 92,780 & 92,780 & 92,780 & 92,780 \\
\hline Mean of Dependent Variable & 1.075 & 0.352 & 0.976 & 167.70 & 0.0095 & 0.0648 & 0.246 \\
\hline
\end{tabular}

Notes 1. Contains RD estimates of the effects of an additional Yelp half-star on dependent variable

2. Standard errors are clustered at the restaurant level

3. Standard errors in column (1) are cluster bootstrapped at the restaurant level

4. Stars denote significance levels: $10 \%(*), 5 \%(* *)$, and $1 \%(* *)$ 